ARTICLE

Received 16 Apr 2015 | Accepted 24 Mar 2016 | Published 25 Apr $2016 \quad$ DOl: 10.1038/ncomms11423

\title{
Phosphotransferase-dependent accumulation of (p)ppGpp in response to glutamine deprivation in Caulobacter crescentus
}

Séverin Ronneau ${ }^{1}$, Kenny Petit ${ }^{1}$, Xavier De Bolle ${ }^{1} \&$ Régis Hallez ${ }^{1}$

The alarmone (p)ppGpp is commonly used by bacteria to quickly respond to nutrient starvation. Although (p)ppGpp synthetases such as SpoT have been extensively studied, little is known about the molecular mechanisms stimulating alarmone synthesis upon starvation. Here, we describe an essential role of the nitrogen-related phosphotransferase system (PTS Ntr) in controlling (p)ppGpp accumulation in Caulobacter crescentus. We show that cells sense nitrogen starvation by way of detecting glutamine deprivation using the first enzyme $\left(\mathrm{EI}^{\mathrm{Ntr}}\right.$ ) of PTS ${ }^{\mathrm{Ntr}}$. Decreasing intracellular glutamine concentration triggers phosphorylation of $\mathrm{El}^{\mathrm{Ntr}}$ and its downstream components $\mathrm{HPr}$ and EllA $\mathrm{A}^{\mathrm{Ntr}}$. Once phosphorylated, both $\mathrm{HPr} \sim \mathrm{P}$ and Ell $\mathrm{A}^{\mathrm{Ntr}} \sim \mathrm{P}$ stimulate (p)ppGpp accumulation by modulating SpoT activities. This burst of second messenger primarily impacts the non-replicative phase of the cell cycle by extending the G1 phase. This work highlights a new role for bacterial PTS systems in stimulating (p)ppGpp accumulation in response to metabolic cues and in controlling cell cycle progression and cell growth.

\footnotetext{
${ }^{1}$ Bacterial Cell cycle and Development (BCcD), URBM, University of Namur, 61 Rue de Bruxelles, Namur 5000, Belgium. Correspondence and requests for materials should be addressed to R.H. (email: regis.hallez@unamur.be).
} 
T o face the environmental changes, organisms have developed complex regulatory mechanisms that integrate stimuli and stresses. Once activated, these signalling pathways modulate essential cellular processes such as DNA replication, cell division or cell growth. For example, upon nutrient starvation, yeast cells access to a specific quiescent state that enhances stress resistance and survival ${ }^{1}$. Bacteria also select many strategies to survive in challenging environments. One of the most studied bacterial adaptations to harsh conditions is certainly the formation of endospores in Bacillus subtilis, which requires asymmetric cell division and differentiation of the prespore ${ }^{2}$. Other bacteria take advantage of their asymmetric cell division to adapt to starvation conditions. It is the case of the aquatic $\alpha$-proteobacterium Caulobacter crescentus that divides asymmetrically to give birth to two different daughter cells: a chemotactically active motile swarmer cell and a sessile stalked cell. Whereas the stalked cell grows and reinitiates DNA replication immediately at birth to ultimately divide again, the newborn swarmer cell enters first into a pre-replicative (G1) phase (Fig. 1a). In nutrient-replete conditions, the G1/swarmer cell differentiates into a stalked cell (swarmer-to-stalked transition) and concomitantly initiates chromosome replication (G1-to-S transition) ${ }^{3}$. Upon nitrogen starvation, C. crescentus extends its swarmer phase to promote spreading and colonization of new environments ${ }^{4-6}$. Asymmetric cell division might be a strategy commonly used by $\alpha$-proteobacteria to generate daughter cells with different cell fates ${ }^{7}$.

Nutritional stresses are also known to be associated with the accumulation of an alarmone, the guanosine tetra- and penta-phosphate commonly called (p)ppGpp. Burst of intracellular (p)ppGpp alarmone allows cells to quickly adapt to a nutrient stress by affecting important cellular processes such as transcription, translation or DNA replication (reviewed in refs 8 and 9). For example, (p)ppGpp interferes with cell cycle steps by the direct binding of the alarmone to the DNA primase DnaG, which stops DNA replication in $B$. subtilis ${ }^{10}$. As a consequence of its pivotal role in stress adaptation, (p)ppGpp became crucial for virulence of several bacterial pathogens, long-term persistence, competence and biofilm formation ${ }^{8,9,11}$.

In Escherichia coli, (p)ppGpp level is regulated by two proteins, RelA and SpoT ${ }^{12}$. RelA is a monofunctional (p)ppGpp synthetase stimulated by amino acids starvation, in contrast to SpoT, which is a bifunctional synthetase-hydrolase enzyme responding to a wide range of nutritional stresses such as carbon, phosphate or fatty acid starvation ${ }^{9}$. C. crescentus possesses a single RelA/SpoT homologue 12 that was named SpoT because of its bifunctional activity ${ }^{3,14}$. Previous studies showed that (p)ppGpp can modulate cell cycle progression in C. crescentus by delaying simultaneously the swarmer-to-stalked differentiation and the G1-to-S transition ${ }^{13,15,16}$. Nitrogen or carbon starvation was described to trigger accumulation of (p)ppGpp but the regulatory networks sensing these stresses and activating SpoT remain uncovered ${ }^{13,14}$. Furthermore, interacting partners of $\mathrm{SpoT}_{\mathrm{Cc}}$ are largely unknown even if $\mathrm{SpoT}_{\mathrm{Cc}}$ was shown to co-fractionate with the 70 S ribosomal subunit ${ }^{14}$.

Ammonium $\left(\mathrm{NH}_{4}^{+}\right)$is the preferred inorganic nitrogen source for most of living cells. There are only two reactions that efficiently assimilate $\mathrm{NH}_{4}^{+}$(Fig. 1b). The first one is catalysed by the NADPdependent assimilative glutamate dehydrogenase. The other one is mediated by the ATP-dependent glutamine synthetase $(\mathrm{Gln} A)$. There is no NADP-dependent glutamate dehydrogenase encoded in the genome of C. crescentus, suggesting that the assimilation of inorganic nitrogen is strictly dependent on the glutamine synthetase $(\mathrm{Gln} A)$ activity. In most bacteria, nitrogen metabolism is tightly regulated by a well-characterized pathway, which involves the universal nitrogen sensor GlnD (Fig. 1b, reviewed in refs 17 and 18). When E. coli is grown in nitrogen-deplete $(-\mathrm{N})$ conditions, the PII uridyltransferase GlnD catalyses the transfer of uridine monophosphate (UMP) groups to PII regulatory proteins, $\mathrm{G} \ln \mathrm{B}$ and $\mathrm{GlnK}$. GlnK $\sim \mathrm{UMP}$ no longer inhibits the ammonia channel $A m t B$, and $G \ln B \sim$ UMP stimulates deadenylylation of GlnA by the adenylyltransferase GlnE, and thereby promotes glutamine synthetase activity (Fig. 1b). In nitrogen-replete $(+\mathrm{N})$ conditions, GlnB inhibits the transcription of $g \ln A$, by stimulating dephosphorylation of the transcriptional activator $\mathrm{NtrC}$, and promotes the addition of the adenine monophosphate groups by $\mathrm{G} \ln \mathrm{E}$ to $\mathrm{G} \ln \mathrm{A}$, which slows down the glutamine synthetase activity (Fig. 1b).

In this work, we unravel the regulatory network that stimulates (p)ppGpp accumulation in C. crescentus in response to nitrogen starvation. In particular, we uncover the essential role of the nitrogen-related phosphoenolpyruvate (PEP) phosphotransferase system $\left(\mathrm{PTS}^{\mathrm{Ntr}}\right)$ in transducing glutamine deprivation signal to (p)ppGpp accumulation, which in turn controls the cell cycle progression. The cell cycle control described here constitutes a
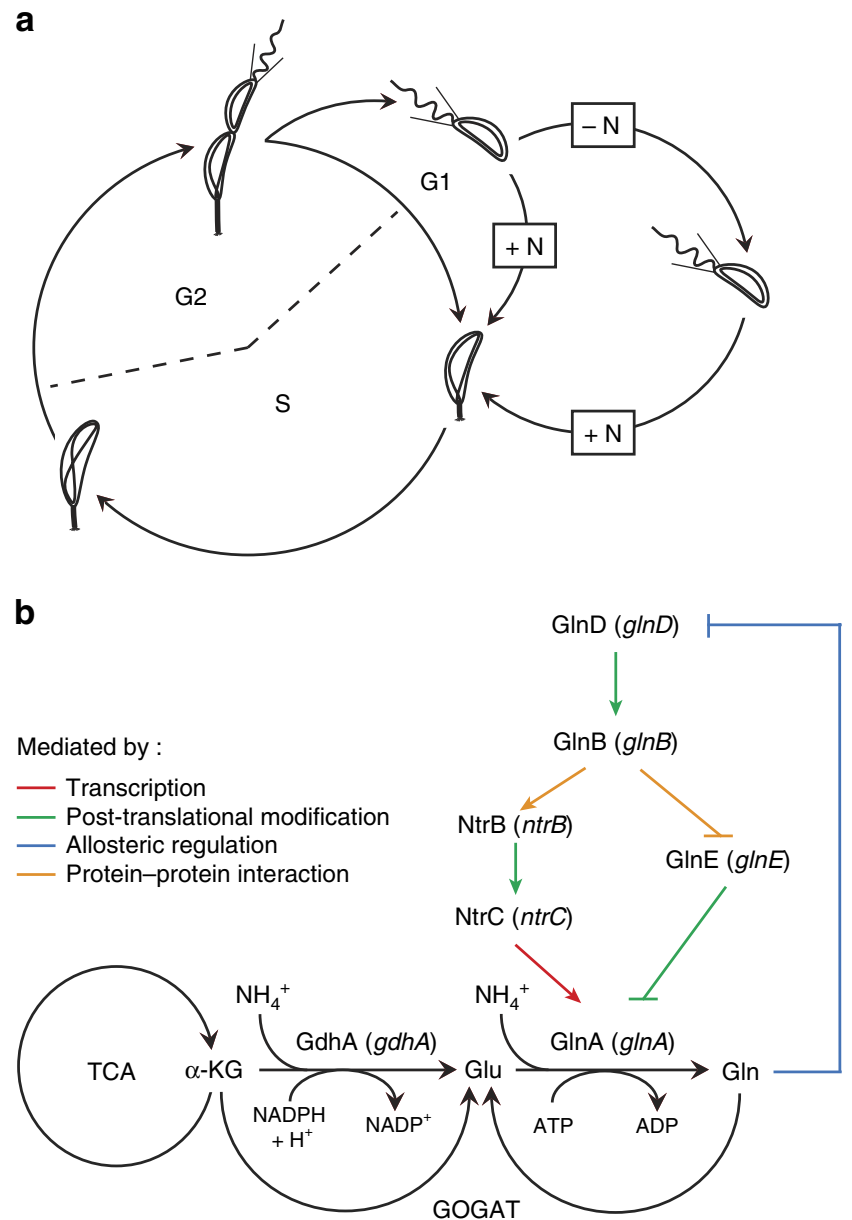

Figure 1 | The $C$. crescentus swarmer cell lifetime is extended upon nitrogen starvation. (a) Asymmetric cell division of $C$. crescentus gives birth to a non-replicative swarmer cell that goes through $\mathrm{G} 1$ phase before replicating and a replicative stalked cell that directly enters into $S$ phase. Upon nitrogen starvation ( $-N$ ), swarmer cells extend their G1 phase. (b) In E. coli, ammonium can be assimilated either by the NADP-dependent glutamate dehydrogenase ( $\mathrm{GdhA}$ ) to generate glutamate (Glu) from $\alpha$-ketoglutarate $(\alpha-K G)$ or by the glutamine synthetase $(G \ln A)$ to produce glutamine (GIn) from Glu, this latter being recycled by the glutamate synthase (GOGAT). GInA is regulated at different levels by the $\mathrm{G} \ln D / G \ln B /$ $\mathrm{G} \ln \mathrm{E}$ and NtrBC pathways, and $\mathrm{G} \ln D$ senses intracellular pool of $\mathrm{G} \ln$. 
new PTS ${ }^{\mathrm{Ntr}}$-dependent regulatory role, illustrating the diversity of the cellular processes regulated by PTS systems.

\section{Results}

Glutamine deprivation signals nitrogen starvation. Previous studies showed that nitrogen starvation extends the swarmer cell lifetime in C. crescentus $^{4-6}$. By following DNA content and cell cycle-regulated proteins (the flagellin and the stalked-associated protein StpX) in synchronous or asynchronous population of Caulobacter cells, we confirmed the specific extension of the G1/swarmer phase in response to nitrogen starvation (Supplementary Fig. 1a-e). By contrast, stalked cells can complete DNA replication once initiated, despite the absence of a nitrogen source (Supplementary Fig. 1f).

To understand how nitrogen starvation affects the differentiation of G1/swarmer cells, we focused our work on proteins involved in nitrogen assimilation and metabolism. First, we created an in-frame deletion of the predicted gene coding for the general sensor for nitrogen availability, $g \ln D$ (CCNA_00013). In contrast to wild-type cells, $\Delta g \ln D$ cells were unable to use ammonium as a nitrogen source. Indeed, the $\Delta g \ln D$ mutant did not grow and accumulated G1/swarmer cells when ammonium was used as the sole nitrogen source (Supplementary Fig. 2a,b). As expected, the G1 block and the growth were rescued in the presence of glutamine (Supplementary Fig. 2). Indeed, as for $g \ln D$ mutants in E. coli ${ }^{19}$, C. crescentus $\Delta g \ln D$ is auxotrophic for glutamine. Thus this result shows that G1/swarmer cells accumulation in $\Delta g \ln D$ is a consequence of its inability to use ammonium as a nitrogen source. Interestingly, the $\Delta g \ln D$ mutant strain cultivated in a complex peptone yeast extract (PYE) medium accumulated G1/swarmer cells (Fig. 2c,d). As a consequence, $\Delta g \ln D$ cells also exhibited (i) a slower growth than the wild-type strain and (ii) a bigger motility halo than the wild-type, despite the growth defect (Fig. 2a,b). Indeed, the overrepresentation of the G1/swarmer cells in a $\Delta g \ln D$ population increases the overall motility and the doubling time of the strain. Thus, our results indicate that G1/swarmer lifetime is extended in the absence of $g \ln D$ (Fig. $2 \mathrm{a}-\mathrm{d}$ ). Again, addition of glutamine suppressed all these phenotypes (Fig. 2d), suggesting that defects of $\Delta g \ln D$ are a consequence of glutamine availability in the complex PYE medium. Indeed, PYE is mainly composed of yeast extract, in which glutamine is the less-abundant amino acid ( $\leq 0.2 \%$, see the 'Methods' section).

In $E$. coli, glutamine auxotrophy displayed by $g \ln D$ mutant strains comes from the under-expression and lower activity of the glutamine synthetase $\mathrm{G} \ln \mathrm{A}$. In the absence of $\mathrm{GlnD}$, the PII protein $G \ln B$ is not uridylylated, and thereby constitutively stimulates (i) the dephosphorylation of transcriptional activator $\mathrm{NtrC} \sim \mathrm{P}$ by $\mathrm{NtrB}$, which subsequently inhibits the $\mathrm{NtrC} \sim \mathrm{P}$ dependent expression of $g \ln A$, and (ii) the adenylylation (+ adenine monophosphate) of GlnA by the adenylytransferase GlnE, thereby inhibiting the glutamine synthetase activity (Fig. 1b). C. crescentus encodes three PII protein homologues $(g \ln B$ CCNA_02046, $g \ln K \quad$ CCNA_01400 and $g \ln C$ CCNA_00555), one adenylytransferase homologue ( $g \ln E$ CCNA_02839), three GlnA homologues ( $\ln A$ CCNA_02047, $g \ln A_{2}$ CCNA_03230 and $g \ln A_{3}$ CCNA_03240) and two NtrC homologues (ntrC CCNA_01815, and $n t r X$ CCNA_01817). Single in-frame deletions of each of these genes were created and tested for growth, motility and G1 accumulation in complex PYE medium. We found that only $\Delta g \ln B, \Delta n t r C$ and $\Delta g \ln A$ recapitulated $\Delta g \ln D$ phenotypes, and that all these phenotypes could be suppressed by adding glutamine to the medium (Fig. 2d). However, it is noteworthy that the motility defect in $\Delta n t r C$ was not completely rescued by
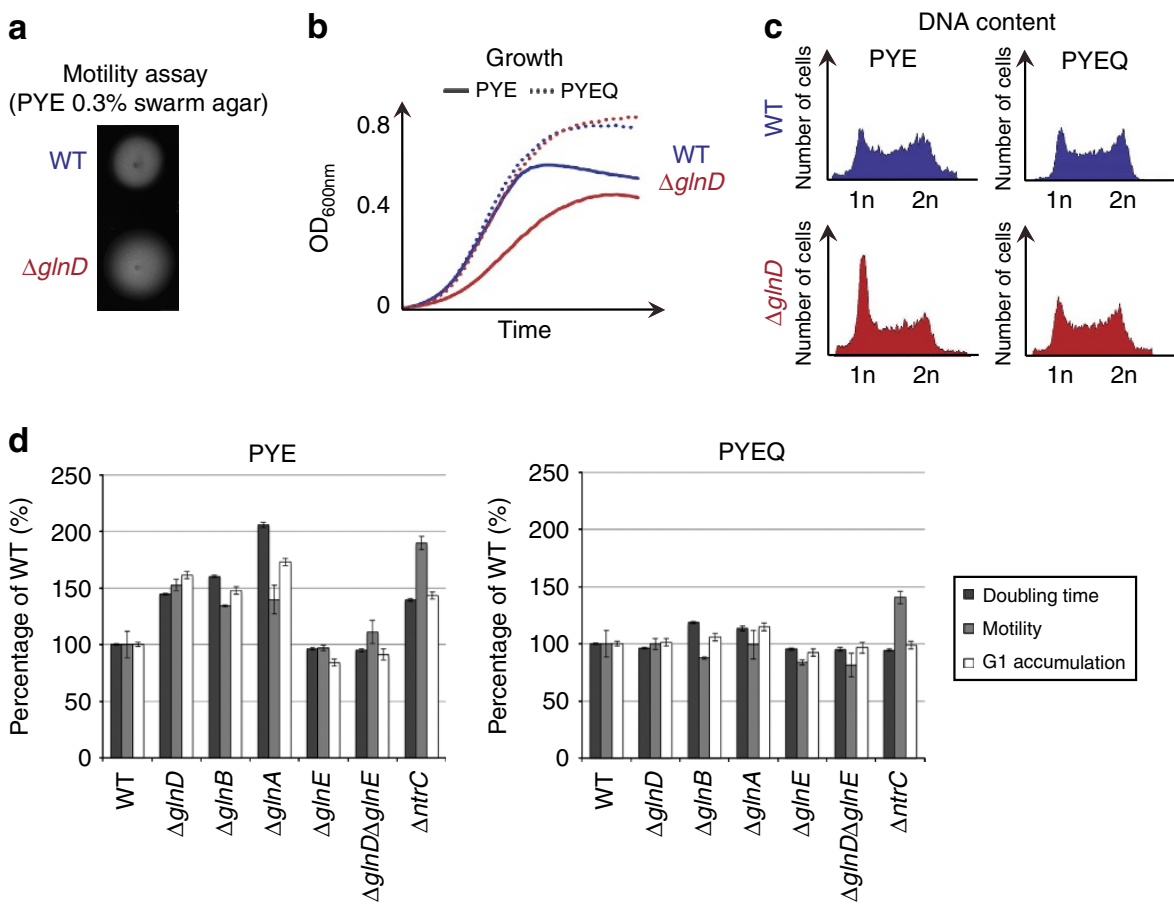

Figure 2 | The $\mathbf{C}$. crescentus G1/swarmer cell lifetime is dictated by intracellular glutamine concentration. (a-d) Extension of the G1/swarmer lifetime in a $\Delta g \ln D$ strain can be compensated by addition of glutamine. Motility (a), growth (b) and DNA content (c) of wild-type (WT; RH50) and $\Delta g / n D$ (RH577) grown in complex media without (PYE) or with glutamine (PYEQ) media. (d) G1/swarmer lifetime is extended in glutamine auxotrophic mutants. Doubling time, motility and G1 proportion were measured in WT (RH50), $\Delta g \ln D(\mathrm{RH} 577), \Delta g \ln B(\mathrm{RH} 771), \Delta g \ln A(\mathrm{RH} 772), \Delta g \ln E(\mathrm{RH} 874), \Delta g \ln D \Delta g \ln E(\mathrm{RH} 875)$ and $\Delta n \operatorname{trC}(\mathrm{RH} 1458)$ grown in complex media without (PYE) or with glutamine (PYEQ), and normalized to the WT (100\%). All these phenotypes can be rescued by addition of glutamine (PYEQ). Error bars $=$ s.d.; $n=3$. 
addition of glutamine, suggesting that $\mathrm{NtrC}$ also controls motility independently of G1/swarmer cells accumulation (Fig. 2d). Moreover, deleting $g \ln E$ alleviated the $\Delta g \ln D$ defects, supporting the fact that inactivation (adenylylation) of GlnA by GlnE is the causative effect of the glutamine auxotrophy detected in $\Delta g \ln D$ cells (Fig. 2d). Unexpectedly, neither $\mathrm{Gln}_{2}$ nor $\mathrm{Gln}_{3}$ seems to participate in glutamine synthesis, at least in the conditions used here (Supplementary Fig. 3a,b). Finally, a catalytic mutant inactivating the glutamine synthetase activity of $\mathrm{Gln} A$ $\left(\mathrm{Gln}_{\mathrm{R} 360 \mathrm{~A}}\right)$ phenocopied $\Delta g \ln A$ in terms of glutamine auxotrophy, growth defect and G1 accumulation (Supplementary Fig. 3c,d), and all these defects can be suppressed by the addition of glutamine or complemented with a wild-type copy of $\ln A$ expressed in trans (Supplementary Fig. 3d,e). Altogether, these data support that (i) glutamine deprivation constitutes the signal for nitrogen starvation and that (ii) intracellular levels of glutamine drive the cell cycle progression of $C$. crescentus.

Cell cycle response to nitrogen starvation requires (p)ppGpp. To fish out key actors participating to the G1/swarmer extension in response to glutamine deprivation, we isolated spontaneous mutations that increase motility of the wild-type strain on PYE swarm agar plates supplemented with glutamine. Whole-genome sequencing of one candidate revealed a unique mutation (D81G) in the hydrolase domain of SpoT, the protein synthesizing (p)ppGpp (Fig. 3a and Supplementary Fig. 4a). It has been shown that mutations abolishing, at least partially, the hydrolase activity of SpoT without altering its synthetase activity, were all found in the hydrolase domain ${ }^{20}$. Interestingly, the conserved aspartate, corresponding to the D81 in C. crescentus SpoT, was found to be required for the hydrolase activity of SpoT in Streptococcus dysgalactiae $^{20}$, which suggests that the D81G mutation may reduce hydrolase activity of SpoT in C. crescentus as well. The $s p o T_{D 81 G}$ strain had a growth delay in PYE and accumulated G1/ swarmer cells in exponential phase of growth (Fig. 3b; Supplementary Fig. 5a-c and Supplementary Movie 1), even when glutamine was added to the medium (Supplementary Figs $5 \mathrm{a}-\mathrm{c}$ and 6), confirming that the $s p o T_{D 81 G}$ mutant is insensitive to glutamine. By contrast, in-frame deletion of spoT $(\triangle s p o T)$ displayed a motility defect on swarm agar and contained less G1/swarmer cells, in comparison with the wild-type (Fig. 3b; Supplementary Fig. 5b,c and Supplementary Movie 1). Most importantly, introducing $\Delta s p o T$ in $\Delta g \ln D$ cells completely a

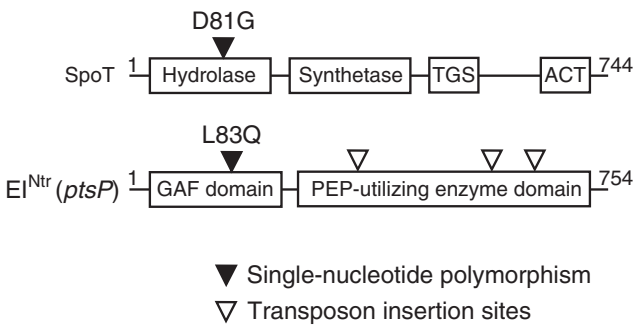

b

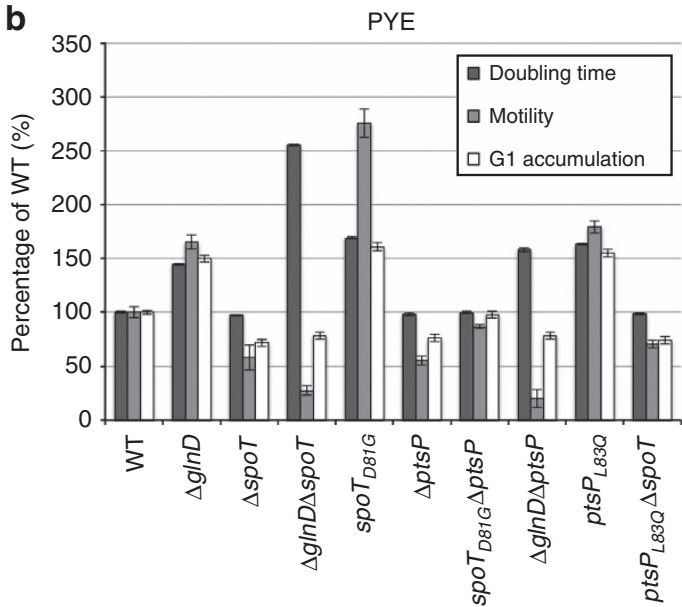

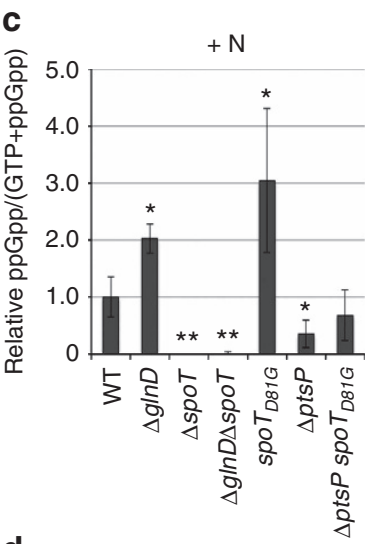

d

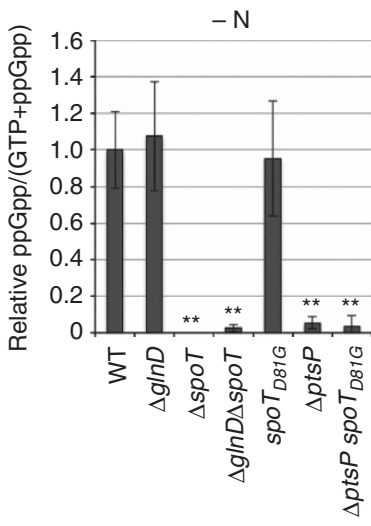

Figure 3 | SpoT and El ${ }^{\text {Ntr }}$ modulate (p)ppGpp accumulation on nitrogen starvation. (a) Mutations isolated in SpoT and El ${ }^{\text {Ntr }}$ that modulate G1/swarmer lifetime. Black arrowheads indicate the mutations ( $s_{00} T_{D 81 G}$ and $p t s P_{L 83 Q}$ ) that increase $\mathrm{G} 1 /$ swarmer lifetime. White arrowheads indicate the positions of 3 himar transposon insertions in the pts $P$ locus out of the 16 that suppressed spoT $T_{D 81 G}$ phenotypes. The exact positions of the remaining 13 transposon insertions into the ptsP locus were not determined. (b) SpoT and EI ${ }^{\mathrm{Ntr}}$ control G1/swarmer lifetime. Doubling time, motility and G1 proportion were measured in wild-type (WT; RH50), $\Delta g \operatorname{lnD}$ (RH577), $\Delta$ spoT (RH1755), $\Delta g \operatorname{lnD} \Delta$ spoT (RH1756), spoT $T_{D 81 G}(\mathrm{RH} 1752), \Delta p t s P$ (RH1758), $\Delta p t s P$ spoT D81G $(\mathrm{RH} 1727) \Delta g \mathrm{InD} \Delta \mathrm{pts} P(\mathrm{RH} 1940), \mathrm{pts} P_{\mathrm{L} 83 \mathrm{Q}}(\mathrm{RH} 1748)$ and $\Delta$ spoT ptsP $P_{\mathrm{L} 83 \mathrm{Q}}(\mathrm{RH} 1728)$ grown in complex media (PYE) and normalized to the WT (100\%). Error bars =s.d.; $n=3$. (c,d) Glutamine auxotrophy leads to (p)ppGpp accumulation. Intracellular levels of (p)ppGpp detected by TLC after nucleotides extraction of WT (RH50), $\Delta g \operatorname{lnD}(\mathrm{RH} 577), \Delta$ spoT (RH1755), $\Delta g \operatorname{lnD} \Delta$ spoT (RH1756), spoT D81G $(\mathrm{RH} 1752), \Delta p t s P(\mathrm{RH} 1758)$ and $\Delta p t s P$ spoT $T_{\text {D81G }}(\mathrm{RH} 1727)$ grown (c) in $+\mathrm{N}$ or $(\mathbf{d})-\mathrm{N}$ conditions. Error bars $=$ s.d.; $n=3$. Statistically significant differences by Student's $t$-test in comparison with the WT are indicated as ${ }^{\star} P<0.05 \%$ and ${ }^{*} P<0.01 \%(n=3)$. 
suppressed the accumulation of G1/swarmer cells (Fig. $3 \mathrm{~b}$ and Supplementary Fig. 5b,c). This result highlights the role of (p)ppGpp produced by SpoT in response to glutamine deprivation to control the cell cycle. We thus checked the (p)ppGpp production in $-\mathrm{N}$ or $+\mathrm{N}$ conditions. In agreement with previous studies ${ }^{14}$, we found that (p)ppGpp concentration increases on glutamine deprivation, that is, in the wild-type strain grown without nitrogen source $(-\mathrm{N})$ or in $\Delta g \ln D$ cultivated with $(+\mathrm{N})$ or without $(-\mathrm{N}) \mathrm{NH}_{4}^{+}$(Fig. 3c,d; Supplementary Figs $1 \mathrm{~g}$ and $5 \mathrm{~d}$ ). As already mentioned in previous works ${ }^{13,15}$, we also observed a low amount of (p)ppGpp produced by wild-type cells in non-stressed conditions (Fig. 3c and Supplementary Fig. 5d). This (p)ppGpp steady-state level was slightly higher in the $s p o T_{D 81 G}$ strain in $+\mathrm{N}$ conditions (Fig. $3 \mathrm{c}$ and Supplementary Fig. 5d), which would explain the phenotypes displayed by $s p o T_{D 81 G}$, that is, slower growth, bigger motility halo and G1 accumulation (Fig. 3b), even in the presence of glutamine (Supplementary Figs 5a-c and 6). Nevertheless, spoT $T_{D 81 G}$ cells accumulated similar levels of (p)ppGpp than wild-type cells upon nitrogen starvation $(-\mathrm{N})$, suggesting that $\mathrm{SpoT}_{\mathrm{D} 81 \mathrm{G}}$ is still sensitive to nitrogen starvation (Fig. 3d). In contrast, the disappearance of (p)ppGpp accumulated upon nitrogen starvation is slower in $s p o T_{D 81 G}$ cells than in wildtype cells (Supplementary Fig. 5e). These results support that D81G mutation mainly affects the hydrolase activity of SpoT. It's noteworthy that an artificial increase of (p)ppGpp levels in nonstarved cells displayed similar phenotypes than $s{ } T_{D 81 G}$ in complex medium PYE ${ }^{16}$. The fact that, in non-stressed conditions, a strain producing more (p)ppGpp $\left(s p o T_{D 81 G}\right)$ accumulated G1/ swarmer cells, whereas a strain producing no (p)ppGpp at all $(\Delta s p o T)$ contained less $\mathrm{G1} / \mathrm{swarmer}$ cells (Fig. $3 \mathrm{~b}, \mathrm{c})$, suggest that (p)ppGpp steady-state level might determine the time spent by swarmer cells in G1 phase. Altogether, our findings indicate that glutamine deprivation increases (p)ppGpp level, which in turn, will extend the lifetime of G1/swarmer cells.

PTS ${ }^{\mathrm{Ntr}}$ promotes (p)ppGpp accumulation on nitrogen starvation. To identify factors that participate to the activation of SpoT in response to nitrogen starvation, we selected for transposon insertions that improve growth of $s p o T_{D 81 G}$ cells on complex medium (PYE). Indeed, the accumulation of (p)ppGpp in $s p o T_{D 81 G}$ cells decreases the growth rate on PYE medium (Fig. 3b and Supplementary Fig. 5a). We identified multiple transposon insertions (34 out of 50 clones) into spoT $T_{D 81 G}$ itself. The remaining 16 clones harboured a transposon insertion into the ptsP gene (CCNA_00892), coding for a nitrogen-related PEP-phosphotransferase (PTS) protein homologue, called PtsP or $\mathrm{EI}^{\mathrm{Ntr}}$ in Enterobacteria (Fig. 3a). Canonical PTS systems are composed of several components that form a phosphorylation cascade initiated by autophosphorylation of the first protein called EI, using PEP as phosphoryl donor (reviewed in ref. 21). The phosphoryl group is then transferred from EI $\sim \mathrm{P}$ to $\mathrm{HPr}$ and then to EIIA proteins. When the PTS system is used to take up sugars, the phosphoryl group is ultimately transferred from EIIA $\sim \mathrm{P}$ to transported carbohydrates by using specific permeases (EIIB and EIIC components). In many other cases, PTS systems are dedicated to regulatory functions implying that PTS components (EI, $\mathrm{HPr}$ or EIIA) phosphorylate or interact with regulatory target proteins ${ }^{21}$. Nitrogen-related PTS (PTS ${ }^{\mathrm{Ntr}}$ ) systems are so far considered as unusual PTS systems that respond to nitrogen availability, but their regulatory roles in bacterial physiology remain poorly understood (reviewed in ref. 21).

An in-frame deletion of $p t s P$ in the parental $s p o T_{D 81 G}$ strain suppressed the $s p o T_{D 81 G}$ phenotypes, confirming the genetic interaction between $p t s P$ and $s p o T_{D 81 G}$ (Fig. $3 \mathrm{~b}$ ). In addition, $\Delta p t s P$ phenocopied $\Delta s p o T$ in terms of motility, G1/swarmer cells accumulation (Fig. 3b; Supplementary Figs $5 a-c$ and $7 a-c$ ), and capability to suppress G1/swarmers cells accumulation of $\Delta g l n D$ cells (compare $\Delta g \ln D \Delta p t s P$ to $\Delta g \ln D \Delta s p o T$ in Fig. 3b; Supplementary Figs $5 \mathrm{a}-\mathrm{c}$ and $7 \mathrm{a}-\mathrm{c}$ ). Interestingly, we isolated another candidate than $s p o T_{D 81 G}$ in the gain-of-motility screen, which harboured a mutation (L83Q) in the GAF domain of $\mathrm{EI}^{\mathrm{Ntr}}$ $\left(p t s P_{L 83 Q}\right.$; Fig. 3a). As $p t s P_{L 83 Q}$ phenocopies $s p o T_{D 81 G}$ (Fig. 3b; Supplementary Figs $5 \mathrm{a}-\mathrm{c}$ and $7 \mathrm{a}-\mathrm{c}), \Delta p t s P$ suppresses $s p o T_{D 81 G}$ defects and $\Delta s p o T$ suppresses $p t s P_{L 83 Q}$ defects (Fig. 3b), we wondered whether $p t s P\left(\mathrm{EI}^{\mathrm{Ntr}}\right)$ is upstream or downstream of spoT. To test that, we measured the (p)ppGpp levels in a $s p o T_{D 81 G}$ $\Delta p t s P$ background. As shown in Fig. 3d, no (p)ppGpp accumulation was detected in $s p o T_{D 81 G} \Delta p t s P$ cells starved for nitrogen $(-\mathrm{N})$. However, $s p o T_{D 81 G} \Delta p t s P$ cells still produced a low amount of (p)ppGpp, whether a nitrogen source was added to the medium or not (Fig. 3c). This constitutive low levels of (p)ppGpp produced by $s p o T_{D 81 G} \Delta p t s P$ cells is very close to the (p)ppGpp level detected in non-starved wild-type cells (Fig. 3c). Interestingly, there is a systematic correlation between the amount of (p)ppGpp produced by the cells and the time spent by these cells in G1 phase. Indeed, $\Delta s p o T$ or $\Delta p t s P$ swarmer cells do not produce detectable levels of (p)ppGpp (Fig. 3c) and have shortened G1 phase (Fig. $3 \mathrm{~b}$ ), whereas spot $T_{D 81 G} \Delta p t s P$ and wild-type cells have similar levels of (p)ppGpp and G1 lifetime (Fig. 3b,c). Altogether, these results support the role played by (p)ppGpp in determining the G1 lifetime, and show that $\mathrm{EI}^{\mathrm{Ntr}}$ regulates (p)ppGpp levels by controlling SpoT.

Glutamine inhibits EI ${ }^{\mathrm{Ntr}}$ autophosphorylation. To understand how glutamine deprivation is transduced to SpoT, we first looked at the autophosphorylation level of $\mathrm{EI}^{\mathrm{Ntr}}$. Indeed, as described above, accumulation of G1/swarmer cells (Fig. 3b) observed in a pts $P_{L 83 Q}$ background, are not compensated by supplying an exogenous source of glutamine (Supplementary Fig. 6). Moreover, it has been recently shown, in the closely related $\alpha$-proteobacterium Sinorhizobium meliloti, that binding of glutamine to the conserved N-terminal GAF domain of $\mathrm{EI}^{\mathrm{Ntr}}$ inhibits its autophosphorylation ${ }^{22}$. To check whether the phosphorylation of $\mathrm{EI}^{\mathrm{Ntr}}$ is also sensitive to glutamine in C. crescentus, we performed in vitro autophosphorylation assays with a purified fraction containing $\mathrm{EI}^{\mathrm{Ntr}}$ using $\left[{ }^{32} \mathrm{P}\right] \mathrm{PEP}$ as a phosphoryl donor, in the presence or absence of glutamine. We found that autophosphorylation of $\mathrm{EI}^{\mathrm{Ntr}}$ was strongly reduced by glutamine (Fig. 4a and Supplementary Fig. 8a). In contrast, autophosphorylation of the $\mathrm{EI}^{\mathrm{Ntr}} \mathrm{L} 83 \mathrm{Q}$ mutant form was not modulated by the presence of glutamine (Fig. 4a), suggesting that the mutation L83Q prevents glutamine binding to the highly conserved region of the $\mathrm{EI}^{\mathrm{Ntr}} \mathrm{GAF}$ domain (Supplementary Fig. 4b).

Phosphorylated PTS ${ }^{\mathrm{Ntr}}$ proteins trigger (p)ppGpp accumulation. To unravel how $\mathrm{EI}^{\mathrm{Ntr}}$ controls SpoT activity, we first searched for components that could participate to PTS ${ }^{\mathrm{Ntr}}$ phosphorelay (Fig. 5a). Besides ptsP $\left(\mathrm{EI}^{\mathrm{Ntr}}\right)$, we found a unique HPr homologue (ptsH, CCNA_00241) and another nitrogen-related PTS ${ }^{\mathrm{Ntr}}$ component, EIIA ${ }^{\mathrm{Ntr}}$ ( $\left.p t s N, C C N A \_03710\right)$. We created single in-frame deletions of the two genes $(\Delta p t s H$ and $\Delta p t s N)$ and found that the proportion of G1/swarmer cells in $\Delta p t s H$ (without $\mathrm{HPr}$ ) or $\Delta p t s N$ (without EIIA ${ }^{\mathrm{Ntr}}$ ) strain was reduced in comparison with the wild-type strain in complex medium (Fig. 5b), a phenotype already described for $\Delta p t s P$ (without $\mathrm{EI}^{\mathrm{Ntr}}$ ) and for $\Delta$ spoT (Fig. 5b). Interestingly, strains expressing a non-phosphorylatable version of EIIA $^{\mathrm{Ntr}}$ (EIIA ${ }^{\mathrm{Ntr}}{ }_{\mathrm{H} 66 \mathrm{~A}}$ ) accumulated G1 cells as much 
a

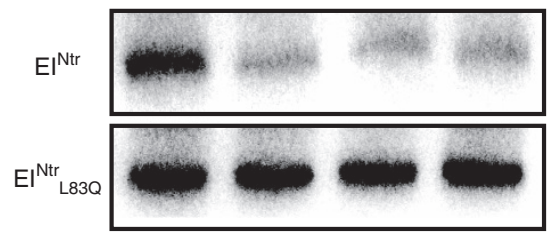

[glutamine]

b

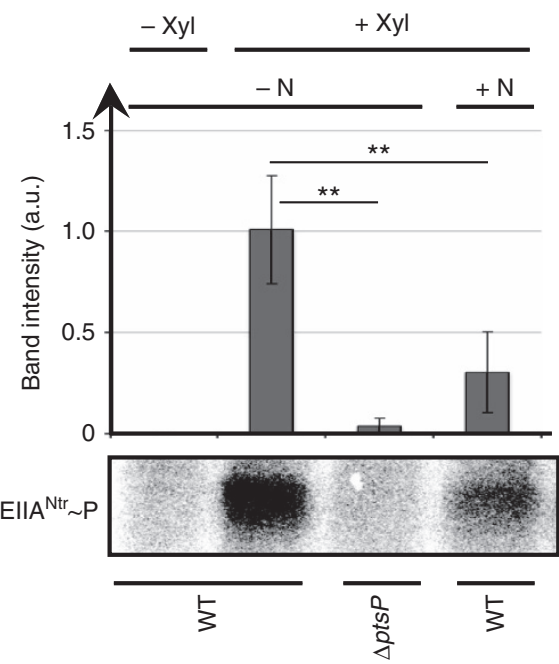

C

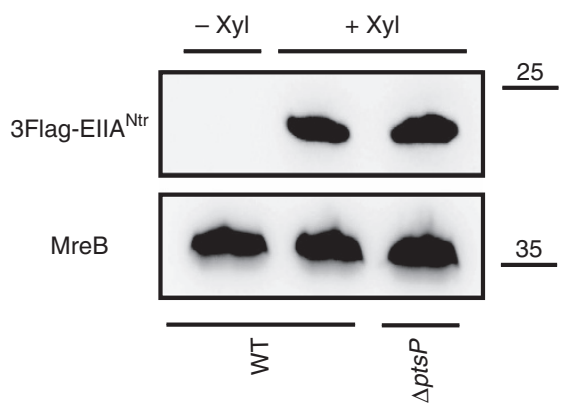

Figure 4 | Glutamine inhibits PTS ${ }^{\text {Ntr }}$ phosphorylation. (a) Glutamine inhibits autophosphorylation of El ${ }^{\mathrm{Ntr}}$ but not El ${ }^{\mathrm{Ntr}}$ L83Q. Autophosphorylation assays of El ${ }^{\mathrm{Ntr}}$ and El ${ }^{\mathrm{Ntr}}{ }_{\text {L83Q }}$ using [ ${ }^{32} \mathrm{P}$ ]PEP as a phosphoryl donor in the absence or presence of increasing concentration of glutamine $(0,2,5$, $10 \mathrm{mM}$ ). The full autoradiography is available in Supplementary Fig. 8a. (b) The ElN ${ }^{\mathrm{Ntr}}$-dependent phosphorylation of Ell/ ${ }^{\mathrm{Ntr}}$ is enhanced upon nitrogen starvation. In vivo phosphorylation assays of EllA ${ }^{\mathrm{Ntr}}$ in $-\mathrm{N}$ or $+\mathrm{N}$ conditions supplemented with $(+\mathrm{Xyl})$ or without $(-\mathrm{Xyl})$ xylose in wildtype (WT) or $\Delta p t s P$ cells expressing 3FLAG-pts N from PxyIX promoter. Error bars $=$ s.d.; $n=3$. Statistically significant differences by Student's $t$-test are indicated as ${ }^{* \star} P<0.01 \%(n=3)$. The full autoradiography is available in Supplementary Fig. 8b. (c) Immunoblotting of protein samples extracted from WT and $\triangle p t s P$ cells expressing 3FLAG-ptsN from PxyIX promoter, incubated $3 \mathrm{~h}$ in M5GG supplemented with $(+X \mathrm{Xl})$ or without $(-X \mathrm{Xl})$ xylose. MreB was detected in all conditions, while 3FLAG-EIIA Ntr was detected only in the presence of xylose. The full blot is available in Supplementary Fig. 8c.

as the loss-of-function mutant $(\Delta p t s N)$, that is, less than the wild-type strain (Fig. 5b), suggesting that the PTS ${ }^{\mathrm{Ntr}}$ pathway is slightly phosphorylated in complex medium PYE and that the last component of the PTS ${ }^{\mathrm{Ntr}}$ phosphorelay, EIIA ${ }^{\mathrm{Ntr}}$, controls SpoT activity.

To validate the conservation of PTS ${ }^{\mathrm{Ntr}}$ phosphorelay and the inhibitory effect of glutamine on this cascade, we checked the phosphorylation level of EIIA ${ }^{\mathrm{Ntr}}$ in $+\mathrm{N}$ or $-\mathrm{N}$ conditions.
To this purpose, we performed in vivo phosphorylation assays on $\mathrm{WT}$ and $\Delta p t s P$ (without $\mathrm{EI}^{\mathrm{Ntr}}$ ) strains expressing a xylose-inducible tagged version of EIIA ${ }^{\mathrm{Ntr}}$ (PxylX::3FLAG-ptsN; Fig. $4 b, c$ and Supplementary Fig. $8 b, c)$. In agreement with our previous data, we found that the phosphorylation of EIIA ${ }^{\mathrm{Ntr}}$ is enhanced in the absence of nitrogen sources $(-N)$ in comparison with the $+\mathrm{N}$ conditions (Fig. $4 \mathrm{~b}, \mathrm{c}$ and Supplementary Fig. 8b,c). In addition, we showed that $\mathrm{EI}^{\mathrm{Ntr}}$ is required in vivo for EIIA ${ }^{\mathrm{Ntr}}$ phosphorylation, since phosphorylated EIIA ${ }^{\mathrm{Ntr}}$ was undetectable in $\Delta p t s P$ cells starved for nitrogen (Fig. 4b,c and Supplementary Fig. 8b,c).

In addition, we measured the (p)ppGpp levels in the single $\mathrm{PTS}^{\mathrm{Ntr}}$ mutants first in $+\mathrm{N}$ conditions. Consistent with the G1 accumulation in PYE, we found that $\mathrm{PTS}^{\mathrm{Ntr}}$ mutant strains $\left(\Delta p t s P, \Delta p t s H, \Delta p t s N\right.$ or $\left.p t s N_{H 66 A}\right)$ produced significantly lower amount of (p)ppGpp than the wild-type strain in the presence of a nitrogen source (Fig. 5c). Moreover, EIIA ${ }^{\mathrm{Ntr}}{ }_{\mathrm{H} 66 \mathrm{~A}}$ partially abrogated the cell cycle and developmental defects of $p t s P_{L 83 Q}$ (EI ${ }^{\mathrm{Ntr}}{ }_{\mathrm{L} 83 \mathrm{Q}}$ ) supporting the fact that overphosphorylation of EIIA $^{\mathrm{Ntr}}$ in $p t s P_{L 83 Q}$ cells is partially responsible for (p)ppGpp accumulation and subsequent G1-to-S transition delay (Fig. 5b). On the contrary, a strain expressing a phosphomimetic mutant of EIIA $^{\mathrm{Ntr}}$ (EIIA $^{\mathrm{Ntr}}{ }_{\mathrm{H} 66 \mathrm{E}}$ ) had increased proportion of G1 cells independently of the presence of $\mathrm{EI}^{\mathrm{Ntr}}$ (Fig. 5b). Altogether, these data suggest that the phosphorylated form of EIIA ${ }^{\mathrm{Ntr}}$ $\left(\mathrm{EIIA}^{\mathrm{Ntr}} \sim \mathrm{P}\right)$ controls SpoT activity.

However, (p)ppGpp measurements in $-\mathrm{N}$ conditions showed that SpoT is also controlled in an EIIA ${ }^{\mathrm{Ntr}} \sim \mathrm{P}$-independent way. Indeed, in contrast to cells devoid of $\mathrm{EI}^{\mathrm{Ntr}}(\Delta p t s P)$ or $\mathrm{HPr}(\Delta p t s H)$, which did not accumulate (p)ppGpp upon nitrogen starvation (Fig. $5 \mathrm{~d}$ ), the absence of EIIA ${ }^{\mathrm{Ntr}} \sim \mathrm{P}$ in $\Delta p t s N$ or $p t s N_{H 66 A}$ cells did not abolish (p)ppGpp accumulation upon nitrogen starvation (Fig. 5d), showing that SpoT is still sensitive to nitrogen availability in the absence of EIIA ${ }^{\mathrm{Ntr}} \sim \mathrm{P}$. On the basis of these results, we propose a model in which $\mathrm{HPr} \sim \mathrm{P}$ controls the intracellular levels of (p)ppGpp by at least two ways, in an EIIA ${ }^{\mathrm{Ntr}} \sim \mathrm{P}$-dependent way but also independently of EIIA ${ }^{\mathrm{Ntr}} \sim \mathrm{P}$.

Phosphorylated EIIA $^{\text {Ntr }}$ directly interacts with SpoT. Since most of the regulatory functions of PTS components are mediated by protein-protein interactions, we checked whether HPr and EIIA $^{\mathrm{Ntr}}$ were able to interact with SpoT by performing bacterial two-hybrid (BTH) assays. To this end, T18 or T25 domains of Bordetella pertussis adenylate cyclase ${ }^{23}$ were fused to coding sequences of $\mathrm{HPr}\left(p t s \mathrm{H}\right.$ and $\left.p t s \mathrm{H}_{H 18 \mathrm{~A}}\right), \mathrm{EIIA}^{\mathrm{Ntr}}\left(p t s \mathrm{~N}, p t s \mathrm{~N}_{H 66 \mathrm{~A}}\right.$ and $\left.p t s N_{H 66 E}\right)$ and SpoT (spoT and $\left.s p o T_{D 81 G}\right)$. We found that both the wild-type EIIA $^{\mathrm{Ntr}}(p t s N)$ and the phosphomimetic mutant of EIIA ${ }^{\mathrm{Ntr}}$ (EIIA ${ }^{\mathrm{Ntr}}{ }_{\mathrm{H} 66 \mathrm{E}}$ ) were able to interact with SpoT versions (Fig. 6a,b and Supplementary Fig. 9a), while the non-phosphorylatable mutant EIIA ${ }^{\mathrm{Ntr}}{ }_{\mathrm{H} 66 \mathrm{~A}}$ was not (Fig. 6a,b and Supplementary Fig. 9a). Both T18-EIIA ${ }^{\mathrm{Ntr}}{ }_{\mathrm{H} 66 \mathrm{~A}}$ and T25-EIIA ${ }_{\text {H66A }}$ can, respectively, interact with $\mathrm{T} 25-\mathrm{HPr}$ and T18-HPr (Fig. 6c and Supplementary Fig. 9a), showing that EIIA $^{\mathrm{Ntr}}{ }_{\mathrm{H} 66 \mathrm{~A}}$ is functional in the BTH assays. Altogether, these findings suggest that EIIA ${ }^{\mathrm{Ntr}}$ is phosphorylated in vivo in E. coli. Indeed, there are two PTS systems in E. coli, a canonical one composed of EI ( $p t s I), \mathrm{HPr}(p t s H)$ and EIIA ( $p t s M)$, as well as a nitrogen-related one composed of $\mathrm{EI}^{\mathrm{Ntr}}(p t s P), \mathrm{NPr}(n p r)$ and EIIA $^{\text {Ntr }}(p t s N)$, and both pathways can cross-talk to some extent $^{24}$ (Supplementary Fig. 9b). To test whether Caulobacter EIIA $^{\mathrm{Ntr}}$ is phosphorylated in vivo in E. coli, strains deleted for $n p r$ (NPr) or for both $p t s P\left(\mathrm{EI}^{\mathrm{Ntr}}\right)$ and $p t s I(\mathrm{EI})$ genes were created. As illustrated on Fig. 6a and Supplementary Fig. 9c, the interaction between EIIA $^{\mathrm{Ntr}}$ and SpoT was abolished in the $\Delta n p r$ strain while EIIA $^{\mathrm{Ntr}}{ }_{\mathrm{H} 66 \mathrm{E}}$ retained the ability to interact with SpoT. Likewise, 
a

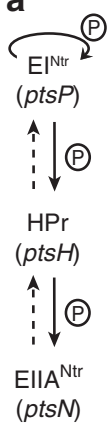

C

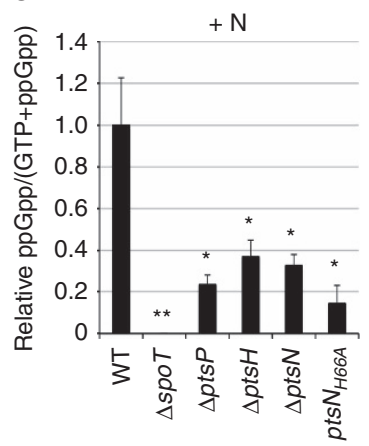

b

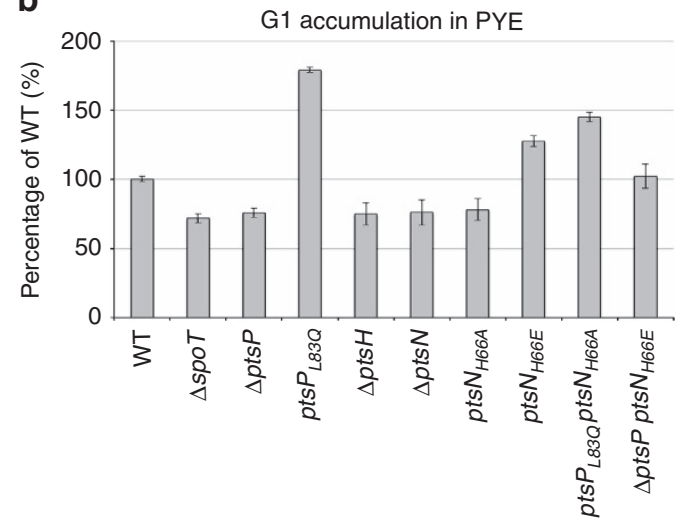

d

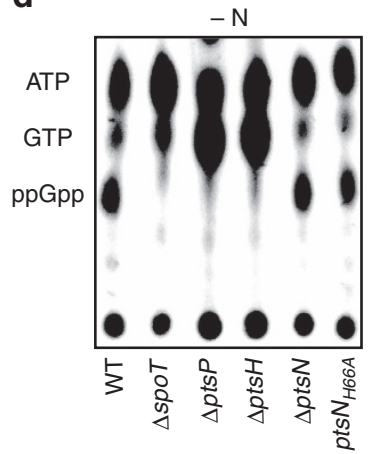

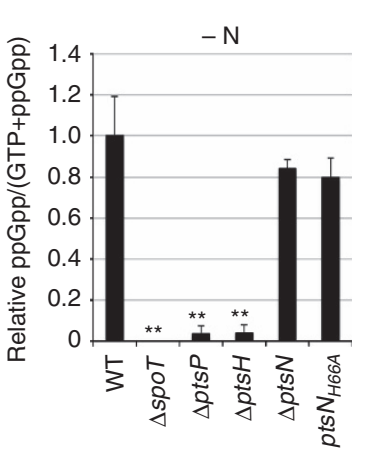

Figure 5 | PTS ${ }^{\text {Ntr }}$ modulates (p)ppGpp accumulation. (a) Schematic representation of the PTS Ntr pathway in C. crescentus. (b) The PTS ${ }^{\text {Ntr }}$ components $\mathrm{EI}^{\mathrm{Ntr}}, \mathrm{HPr}$ and ElIA ${ }^{\mathrm{Ntr}}$ control G1/swarmer lifetime. G1 proportion was measured in wild-type (WT; RH50), $\Delta$ spoT (RH1755), $\Delta$ ptsP (RH1758), ptsP $\mathrm{L}_{\text {L83Q }}$ (RH1748), $\Delta p t s H(R H 1621), \Delta p t s N(R H 1819), p t s N_{H 66 A}(R H 2019), p t s N_{H 66 E}(R H 2017), p t s P_{L 830} p t s N_{H 66 A}(R H 2018), \Delta p t s P$ pts $N_{H 66 E}(R H 2016)$ grown in complex media (PYE) and normalized to the WT (100\%). Error bars =s.d.; $n=3$. (c,d) (p)ppGpp accumulation is modulated by PTS Ntr. Intracellular levels of (p)ppGpp detected by TLC after nucleotides extraction of WT (RH50), $\Delta$ spoT (RH1755), $\Delta$ ptsP (RH1758), $\Delta$ ptsH (RH1621), $\Delta p t s N$ (RH1819) and ptsN $(\mathrm{RH} 2019)$ grown $(\mathbf{c})$ in $+\mathrm{N}$ or $(\mathbf{d})-\mathrm{N}$ conditions. Error bars $=\mathrm{s}$.d.; $n=3$. Statistically significant differences by Student's $t$-test in comparison with the WT are indicated as ${ }^{\star} P<0.05 \%$ and ${ }^{\star} * P<0.01 \%(n=3)$.

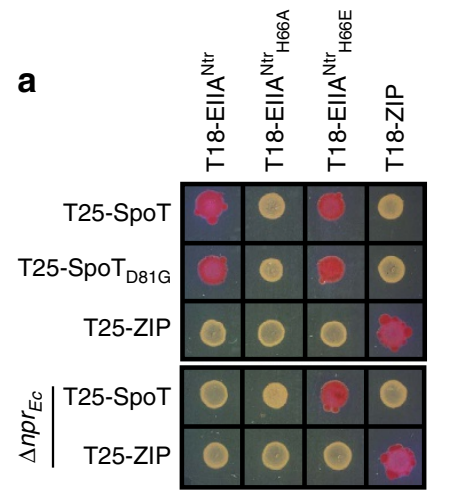

b

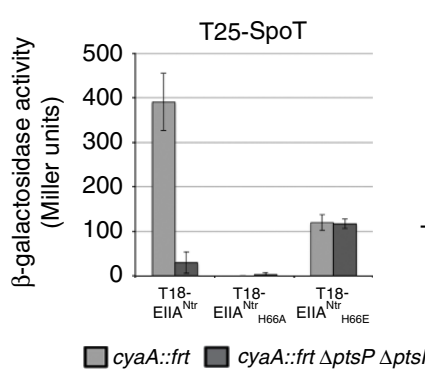

C

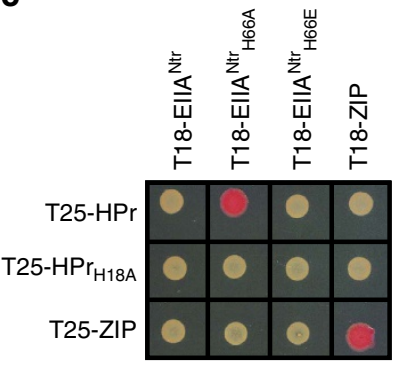

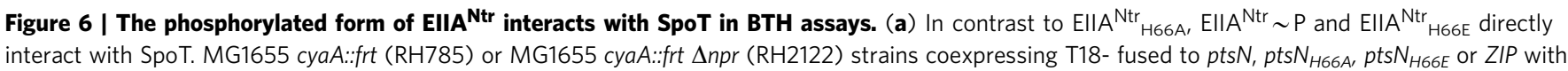
T25- fused to SpoT, SPOT $T_{D 81 G}$ or ZIP were spotted on MacConkey agar base plates supplemented with $1 \%$ maltose and $1 \mathrm{mM}$ IPTG. Plates were incubated for 3-4 days at $30^{\circ} \mathrm{C}$. The red colour indicates positive interactions. (b) The absence of E. coli El and EINtr proteins abolishes interaction between SpoT and

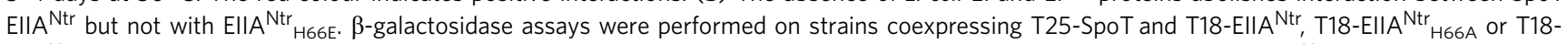
EllA ${ }^{\mathrm{Ntr}}{ }_{\text {H66E, }}$ in the presence (MG1655 cyaA::frt (RH785)) or absence (MG1655 cyaA::frt $\Delta p t s P \Delta p t s I$ (RH2124)) of El and El ${ }^{\text {Ntr }}$ proteins. Error bars = s.d.; $n=3$. (c) In contrast to $\mathrm{HPr}_{\mathrm{H} 18 \mathrm{~A}}, \mathrm{HPr} \sim \mathrm{P}$ directly interacts with ElIA ${ }^{\mathrm{Ntr}}{ }_{\mathrm{H} 66 \mathrm{~A}}$. MG1655 cyaA:.ffrt (RH785) strain coexpressing T18- fused to ptsN, pts $N_{H 66 \mathrm{~A}}$ $p t s N_{\text {H66E }}$ or ZIP with T25- fused to $h p r$, hpr HIIA $_{\text {A }}$ OIP were spotted on MacConkey agar base plates supplemented with $1 \%$ maltose and $1 \mathrm{mM}$ IPTG. Plates were incubated for $3-4$ days at $30^{\circ} \mathrm{C}$. The red colour indicates positive interactions.

no more $\beta$-galactosidase activity was detected in a $\Delta p t s P \Delta p t s I$ background (without E. coli EI proteins) expressing T25-SpoT and T18-EIIA ${ }^{\mathrm{Ntr}}$, while the interaction between SpoT and
EIIA ${ }^{\mathrm{Ntr}}{ }_{\mathrm{H} 66 \mathrm{E}}$ remained unchanged in this background (Fig. 6b). Finally, the expression of Caulobacter ptsH (HPr) from the inducible $\mathrm{pBAD}$ promoter $\left(\mathrm{pBAD} 33-p t s H_{C c}\right)$ in a $\Delta n p r$ 
background restored the interaction between EIIA ${ }^{\mathrm{Ntr}}$ and SpoT only when arabinose was added to the medium (Supplementary Fig. 9c), indicating that Caulobacter HPr and EIIA ${ }^{\mathrm{Ntr}}$ proteins can be phosphorylated by E. coli PTS systems, and that only the phosphorylated form of EIIA ${ }^{\mathrm{Ntr}}$ interacts with SpoT. In contrast to EIIA ${ }^{\mathrm{Ntr}}$, no interaction was detected between $\mathrm{HPr}$ (or $\mathrm{HPr}_{\mathrm{H} 18 \mathrm{~A}}$ ) and SpoT (or $\mathrm{SpoT}_{\mathrm{D} 81 \mathrm{G}}$ ) on MacConkey maltose agar plates (Supplementary Fig. 9d). The fact that HPr interacts with EIIA ${ }^{\mathrm{Ntr}}{ }_{\text {H66A }}$ (Fig. $6 \mathrm{c}$ and Supplementary Fig. 9a) shows that $\mathrm{HPr}$ is functional in the BTH assays.

Altogether, these BTH data strongly suggest that (i) HPr and EIIA $^{\mathrm{Ntr}}$ are both phosphorylated in E. coli and (ii) EIIA ${ }^{\mathrm{Ntr}} \sim \mathrm{P}$ is the only form of EIIA ${ }^{\mathrm{Ntr}}$ able to interact with SpoT, thereby supporting a model in which SpoT activity is controlled directly by $\mathrm{EIIA}^{\mathrm{Ntr}} \sim \mathrm{P}$, and indirectly by $\mathrm{HPr} \sim \mathrm{P}$ (Fig. 8 ).

Phosphorylated EIIA ${ }^{\text {Ntr }}$ inhibits hydrolase activity of SpoT. Interestingly, the deletion of $p t s N$ (EIIA ${ }^{\mathrm{Ntr}}$ ) did not abolish the G1 accumulation of $s p o T_{D 81 G}$ cells in contrast to $\Delta p t s P\left(\mathrm{EI}^{\mathrm{Ntr}}\right)$ or $\Delta p t s H$ (HPr; Fig. 7a). The fact that $S p o T_{\mathrm{D} 81 \mathrm{G}}$, which harbours a reduced hydrolase activity (Supplementary Fig. 5e), is insensitive to the presence of EIIA ${ }^{\mathrm{Ntr}}$ suggests that EIIA ${ }^{\mathrm{Ntr}} \sim \mathrm{P}$ might inhibit the hydrolase activity of SpoT rather than stimulating its synthetase activity. This could explain why $\Delta p t s N$ or $p t s N_{H 66 A}$ are still able to accumulate high levels of (p)ppGpp on nitrogen starvation, while $\Delta p t s P$ or $\Delta p t s H$ cannot (Fig. 5d). To validate our hypothesis, we engineered Caulobacter strains in which the only (p)ppGpp synthetase activity was supplied by the unrelated E. coli RelA protein, and we measured the endogenous hydrolase activity of SpoT in different genetic backgrounds. To this end, we first abolished the synthetase activity of SpoT in several backgrounds $\left(s p o T_{D 81 G}, p t s N_{H 66 A}, p t s N_{H 66 E}\right.$ and $\left.\Delta p t s P\right)$, by replacing the tyrosine 323 of SpoT by an alanine $\left(\right.$ SpoT $_{\mathrm{Y} 323 \mathrm{~A}}$; ref. 14). As expected, all these strains displayed a G1 accumulation similar to a $\Delta$ spoT strain in PYE complex medium (Fig. 7c). In a second time, we inserted a truncated version of E. coli RelA (p)ppGpp synthetase at the xylose locus, leading to an artificial (p)ppGpp accumulation in Caulobacter upon addition of xylose (PxylX:: relA-FLAG; ref. 16). Since the hydrolase domain of RelA is inactive, the only (p)ppGpp hydrolase activity in these strains was carried out by the Caulobacter SpoT protein, while the only (p)ppGpp

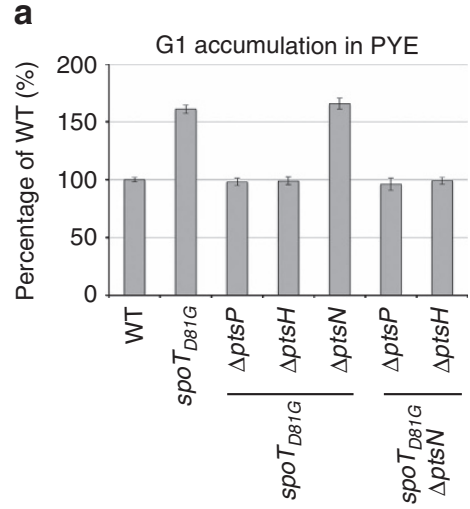

C

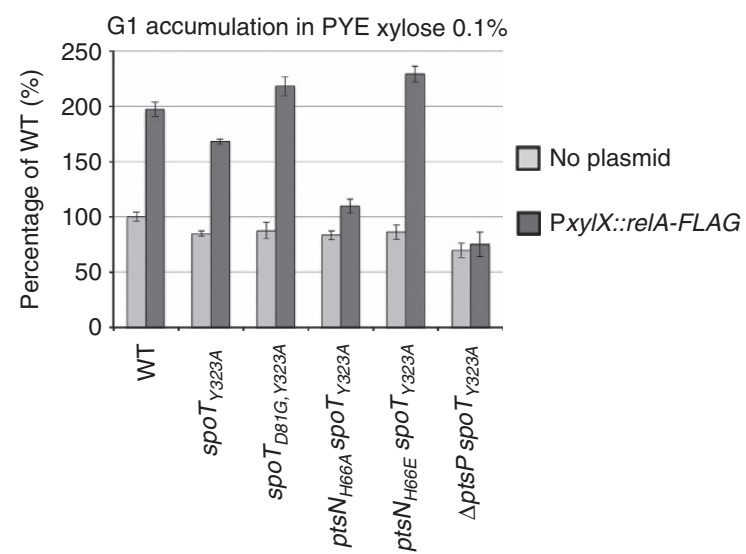

b

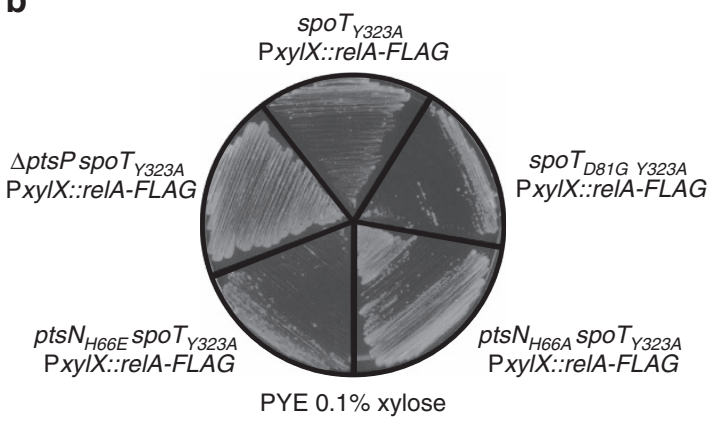

d
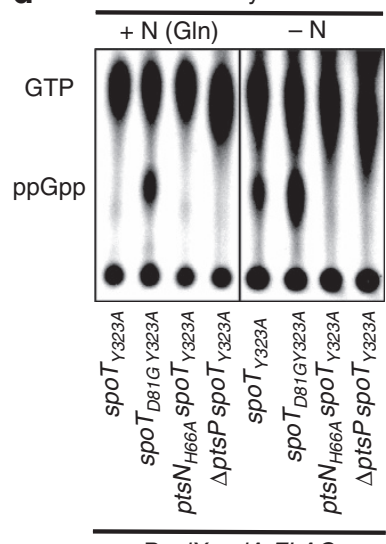

Figure 7 | ElIA ${ }^{\text {Ntr }} \sim \mathbf{P}$ inhibits the hydrolase activity of SpoT. (a) $s p o T_{D 81 G}$ is insensitive to the absence of EllA ${ }^{\text {Ntr }}$. G1 proportion was measured in wild-type

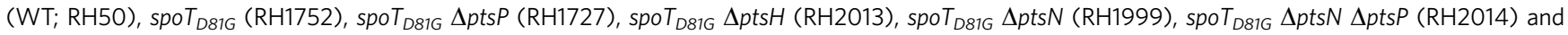
spoT $_{D 81 G} \Delta p t s N \Delta p t s H(R H 2015)$ grown in complex media (PYE) and normalized to the WT (100\%). Error bars $=$ s.d.; $n=3$. (b) The hydrolase activity of

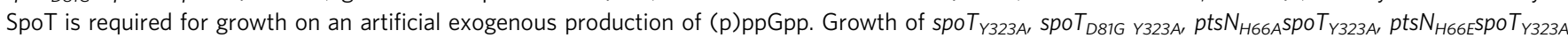
and $\triangle p t s P$ spo $_{Y 323 A}$ expressing a truncated version of $E$. coli relA from the inducible xyIX promoter (PxyIX::relA-FLAG) on PYE medium supplemented with $0.1 \%$ of xylose. (c) Reduction of SpoT hydrolase activity led to a G1 extension on an artificial exogenous production of (p)ppGpp. Flow cytometry analysis to

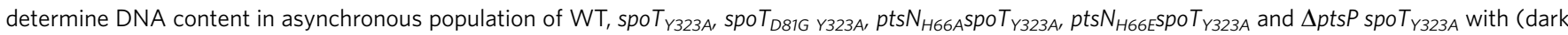
grey bars) or without (light grey bars) PxyIX::relA-FLAG in PYE medium supplemented with $0.1 \%$ of xylose. The data were normalized to the WT without PxyIX::relA-FLAG (100\%). Error bars =s.d.; $n=3$. (d) The hydrolase activity of SpoT is required to degrade (p)ppGpp in $+N$ condition. Intracellular levels of

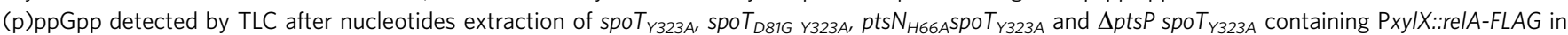
$+\mathrm{N}$ or $-\mathrm{N}$ medium supplemented with $0.1 \%$ xylose. 


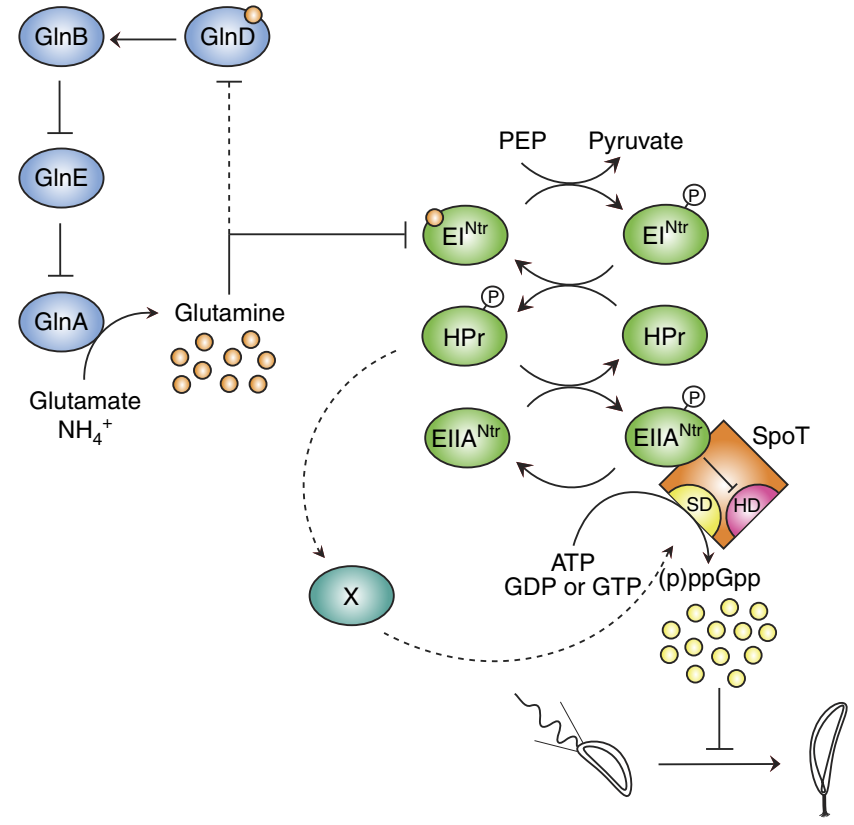

Figure 8 | PTS ${ }^{\text {Ntr }}$-dependent accumulation of (p)ppGpp upon glutamine deprivation. The $\mathrm{G} \ln D / G \ln B / G \ln E$ pathway (in blue) regulates glutamine homoeostasis by modulating GInA (GS) activity. Intracellular glutamine inhibits $\mathrm{El}^{\mathrm{Ntr}}$ autophosphorylation, limiting the (p)ppGpp production in $+\mathrm{N}$ conditions. Note that the $\mathrm{G} \ln D$ activity is very likely also inhibited by intracellular glutamine. On nitrogen starvation, intracellular pool of glutamine drops, relieving inhibition of $\mathrm{El}^{\mathrm{Ntr}}$ autophosphorylation and thereby increasing HPr and EllA ${ }^{\mathrm{Ntr}}$ phosphorylation levels (in green). Once phosphorylated, EllA ${ }^{\mathrm{Ntr}} \sim \mathrm{P}$ interacts with SpoT to inhibit its hydrolase activity $(\mathrm{HD})$, whereas $\mathrm{HPr} \sim \mathrm{P}$ regulates indirectly SpoT synthetase activity (SD). This dual control of SpoT by HPr $\sim \mathrm{P}$ and EllA $\mathrm{A}^{\mathrm{Ntr}} \sim \mathrm{P}$ leads to (p)ppGpp accumulation, which in turn delays the G1-to-S and swarmer-tostalked cell transition.

synthetase activity was supported by the E. coli RelA protein. In the presence of xylose, both spoT $T_{D 81 G ~ Y 323 A}$ and $p t s N_{H 66 E} s p o T_{Y 323 A}$ displayed a growth defect and a G1 accumulation in comparison with the parental $s p o T_{Y 323 A}$ strain (Fig. 7b,c and Supplementary Fig. 10). On the contrary, neither $p t s N_{H 66 A} s p o T_{Y 323 A}$ nor $\Delta p t s P$ $s p o T_{Y 323 A}$ strains had a growth delay or accumulated G1/swarmer cell upon xylose induction. These results strongly suggest that the phosphorylated form of EIIA ${ }^{\mathrm{Ntr}}(p t s N)$ specifically inhibits the hydrolase activity of SpoT. In support of this, we found that upon xylose induction (Fig. 7d), spoT $T_{Y 323 A}$ PxylX::relA-FLAG cells accumulated (p)ppGpp in $-\mathrm{N}$ conditions (that is, when EIIA ${ }^{\mathrm{Ntr}}$ is highly phosphorylated; Fig. $4 \mathrm{~b}$ ), but not in $+\mathrm{N}$ conditions (that is, when EIIA ${ }^{\mathrm{Ntr}}$ is less phosphorylated; Fig. 4b). Furthermore,

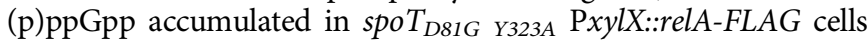
even in $+\mathrm{N}$ conditions (Fig. $7 \mathrm{~d}$ ), supporting again that the $\mathrm{D} 81 \mathrm{G}$ mutation abolishes the hydrolase activity of SpoT. Finally, (p)ppGpp became undetectable in spoT $T_{Y 323 A}$ PxylX::relA-FLAG strains harbouring $p t s N_{H 66 A}$ or $\Delta p t s P$ allele (Fig. $7 \mathrm{~d}$ ), indicating that SpoT hydrolase activity is completely unlocked when EIIA ${ }^{\mathrm{Ntr}}$ is unphosphorylated. Altogether, these findings demonstrate that EIIA $^{\text {Ntr }} \sim \mathrm{P}$ inhibits hydrolase activity of SpoT to modulate (p)ppGpp accumulation upon nitrogen availability.

\section{Discussion}

Adaptation to starvation conditions requires sophisticated regulatory mechanisms that sense an external stimulus and translate it into an internal molecular response. In this report, we uncovered how Caulobacter copes with nitrogen starvation by triggering (p)ppGpp accumulation (Fig. 8), which in turn will control the cell cycle and development by extending the G1/swarmer phase ${ }^{14,16}$. Increasing the time spent in the non-replicative (G1), motile phase reflects the adaptation of Caulobacter cells to their natural environment, that is, freshwater in which nutrients can rapidly be limiting ${ }^{3,4}$. Interestingly, G1 arrest also occurs during the intracellular trafficking of Brucella abortus, and on nitrogen and carbon starvation in Sinorhizobium meliloti $i^{25,26}$. In addition, the G1 block encountered by $S$. meliloti cells starved for nitrogen and carbon is also dependent on (p)ppGpp 26,27 . Therefore, (p)ppGpp-dependent mechanisms delaying DNA replication initiation could be a common feature used by $\alpha$-proteobacteria in response to harsh conditions such as infection or starvation.

As previously suggested in the literature ${ }^{5}$, our data indicate that stalked cells are able to complete replication upon nitrogen starvation, supporting that only swarmer cells are responsive to nitrogen depletion. Indeed, even if the speed of chromosome duplication is slowed down in nitrogen-starved conditions, the stalked cell seems to be unable to stop ongoing DNA replication (Supplementary Fig. 1f). In contrast, the swarmer cell can avoid DNA replication initiation in the same conditions (Supplementary Fig. 1a-e). One reason for this difference could be that initiating DNA replication without enough nitrogen supplies would ultimately be detrimental to the cells. In support of this, we showed that deletion of $s p o T$ is deleterious in a $\Delta g \ln D$ background, since $\Delta g \ln D \Delta s p o T$ strain displays a strong growth defect (Fig. 3b). This result highlights the importance for Caulobacter swarmer cells to delay DNA replication until reaching a critical intracellular nitrogen pool.

Our data established that glutamine deprivation constitutes the intracellular signal perceived by the cell in response to nitrogen starvation and is sufficient to mediate (p)ppGpp accumulation (Fig. 8). Intracellular glutamine concentration is known to vary in bacteria, up to 10 -fold depending on nitrogen availability ${ }^{28}$. As a consequence, monitoring intracellular glutamine concentration is an efficient strategy to evaluate nitrogen availability, and subsequently adjust nitrogen assimilation. In E. coli, the uridylyltransferase GlnD is known to directly sense the intracellular glutamine pool, and according to it, to modify uridylylation level of regulatory PII proteins ( $\mathrm{GlnB}$ and GlnK), which in turn will adapt nitrogen metabolism. For instance, in the absence of glutamine, GlnD will increase ammonium transport, as well as the expression and activity of the glutamine synthetase. Intriguingly, three GlnA paralogs are encoded into the genome of C. crescentus, suggesting a functional redundancy, and the presence of multiple glutamine synthetase is conserved in several $\alpha$-Proteobacteria ${ }^{29}$. Even though we showed that only the glutamine synthetase encoded by $g \ln A$ is necessary for assimilating ammonium in complex and minimal media, we do not exclude that the two other paralogs $\left(G \ln A_{2}\right.$ and $\left.G \ln A_{3}\right)$ display a glutamine synthetase activity under specific growth conditions that remain to be determined. Glutamine synthetase activity has been shown to promote growth of the obligatory intracellular $\alpha$-proteobacterium Ehrlichia chaffeensis inside human cells ${ }^{30}$. Moreover, this successful intracellular growth of E. chaffeensis promoted by the glutamine pool was accompanied by a rapid degradation of $\mathrm{CtrA}$, a cell cycle regulator known to inhibit DNA replication initiation in several $\alpha$-proteobacteria ${ }^{7,31}$. Furthermore, the CtrA level in Caulobacter cells was shown to be maintained upon nitrogen starvation ${ }^{5}$, and even increased upon (p)ppGpp accumulation ${ }^{16}$. These observations suggest that the asymmetrically dividing $\alpha$-proteobacteria might use glutamine as a metabolic cue for nitrogen availability that controls the cell 
cycle thanks to (p)ppGpp alarmone. It would be interesting to check if the PTS ${ }^{\mathrm{Ntr}}$ system is used by other $\alpha$-proteobacteria to relay nitrogen starvation (glutamine deprivation) to (p)ppGpp production and subsequent G1 arrest.

Only a few mechanisms triggering (p)ppGpp accumulation in nutrient-limiting conditions have so far been deciphered at the molecular level ${ }^{8}$. When E. coli cells are starved for amino acids, the (p)ppGpp synthetase RelA is directly activated by ribosomes whose $\mathrm{A}$ site is occupied by an uncharged $\mathrm{tRNA}^{32}$, whereas the bifunctional (p)ppGpp synthetase/hydrolase SpoT is regulated by an acyl carrier protein in response to fatty acid starvation ${ }^{33,34}$. In this report, we discovered a new molecular mechanism stimulating (p)ppGpp accumulation in response to nutrient starvation. This mechanism involves the PTS ${ }^{\mathrm{Ntr}}$ system as an important metabolic sensor that translates a glutamine deprivation signal into a (p)ppGpp accumulation signal. Our data suggest that $\mathrm{EIIA}^{\mathrm{Ntr}} \sim \mathrm{P}$ directly reduces the hydrolase activity of SpoT, while $\mathrm{HPr} \sim \mathrm{P}$ indirectly activates (p)ppGpp production upon nitrogen starvation (Fig. 8). Historically, the PTS system was discovered as a phosphorylation cascade involved in the regulation of sugar uptake and carbon catabolite repression ${ }^{21,35}$. Afterwards, a second phosphotransferase system $\left(\mathrm{PTS}^{\mathrm{Ntr}}\right)$ was proposed to be connected to nitrogen metabolism but this connection remained poorly described ${ }^{21}$. The direct inhibition of $\mathrm{EI}^{\mathrm{Ntr}}$ autophosphorylation by glutamine observed in E. coli and S. meliloti ${ }^{22,36}$, as well as now in C. crescentus (Fig. 4), reinforces the idea that nitrogen constitutes a signal for PTS ${ }^{\mathrm{Ntr}}$ systems. The fact that the GAF domain, highly conserved in all $\mathrm{EI}^{\mathrm{Ntr}}$ proteins (Supplementary Fig. $4 \mathrm{~b}$ ), is required for binding glutamine suggests that the glutamine-dependent control of $\mathrm{EI}^{\mathrm{Ntr}}$ phosphorylation might be a common feature in PTS ${ }^{\mathrm{Ntr}}$ system.

In contrast to its EIIA paralog, the EIIA ${ }^{\mathrm{Ntr}}$ component is not associated with permeases, but rather carries out regulatory functions, by interacting with its target(s). For example, the unphosphorylated form of EIIA ${ }^{\text {Ntr }}$ inhibits pyruvate dehydrogenase activity in Pseudomonas putida by interacting with the E1 subunit ${ }^{37}$. Our work constitutes so far the first example of regulatory functions mediated by the phosphorylated form of EIIA $^{\mathrm{Ntr}}\left(\right.$ EIIA $\left.^{\mathrm{Ntr}} \sim \mathrm{P}\right)$. Indeed, our results support the conclusion that only the phosphorylated form of EIIA ${ }^{\mathrm{Ntr}}$ interacts with SpoT to inhibit its hydrolase activity. This is further supported by the fact that $\mathrm{EI}^{\mathrm{Ntr}}$ and SpoT are found in the same protein complex during stationary phase ${ }^{38}$. Interestingly, a direct interaction between the non-phosphorylated form of EIIA ${ }^{\mathrm{Ntr}}$ and SpoT has been recently found in the $\beta$-proteobacterium Ralstonia eutropha by BTH but no function was assigned for this connection ${ }^{39}$. This differential interaction between phosphorylated or nonphosphorylated form EIIA ${ }^{\mathrm{Ntr}}$ and SpoT illustrates the evolutionary plasticity of PTS ${ }^{\mathrm{Ntr}}$ components with their targets.

Besides EIIA ${ }^{\mathrm{Ntr}} \sim \mathrm{P}$, we know that phosphorylated HPr also controls (p)ppGpp accumulation on nitrogen starvation, but how this regulation works at the molecular level remains an open question. $\mathrm{HPr} \sim \mathrm{P}$ could interact with an unknown factor (X in Fig. 8), which in turn could modulate the abundance of SpoT or activate its synthetase activity, to subsequently increase the global (p)ppGpp pool. Although we have now uncovered the pathway that stimulates (p)ppGpp accumulation in response to nitrogen starvation, understanding how (p)ppGpp affects the G1-to-S transition at the molecular level will be a challenge for future work.

\section{Methods}

Bacterial strains and growth conditions. Oligonucleotides, strains and plasmids used in this study are listed in Supplementary Tables 1, 2 and 3, altogether with construction details provided in the Supplementary Methods. E. coli Top10 was used for cloning purpose, and grown aerobically in Luria-Bertani (LB) broth (Sigma $)^{40}$. Electrocompetent cells were used for transformation of $E$. coli.
All Caulobacter crescentus strains used in this study are derived from the synchronizable wild-type strain NA1000, and were grown in PYE or synthetic M2 $\left(20 \mathrm{mM} \mathrm{PO}_{4}^{3-}, 9.3 \mathrm{mM} \mathrm{NH}_{4}^{+}\right.$; + N) or P2 $\left(20 \mathrm{mM} \mathrm{PO}_{4}^{3-} ;-\mathrm{N}\right)$ supplemented with $0.5 \mathrm{mM} \mathrm{MgSO}_{4}, 0.5 \mathrm{mM} \mathrm{CaCl}_{2}, 0.01 \mathrm{mM} \mathrm{FeSO}_{4}$ and $0.2 \%$ glucose (M2G or $\mathrm{P} 2 \mathrm{G}$, respectively) media at $28-30^{\circ} \mathrm{C}$. Glutamine (Q) was used at a final concentration of $9.3 \mathrm{mM}$. Growth was monitored by following the OD $(600 \mathrm{~nm})$ during $24 \mathrm{~h}$, in an automated plate reader (Bioscreen C, Lab Systems) with continuous shaking at $30^{\circ} \mathrm{C}$. Genes expressed from the inducible van $A$ promoter $\left(\mathrm{P}_{\text {van }}\right)$ was induced with $0.5 \mathrm{mM}$ vanillate. Generalized transduction was performed with phage $\Phi \mathrm{Cr} 30$ according to the procedure described in ref. 41 . Motility was monitored on PYE swarm (0.3\% agar) plates. Area of the swarm colonies were quantified with ImageJ software as described previously in ref. 42 . Motility screen was performed on PYE swarm ( $0.3 \%$ agar) plates supplemented with glutamine $(9.3 \mathrm{mM})$ during $3-4$ days at $30^{\circ} \mathrm{C}$. Genomic DNA of the candidates was then sequenced by the Illumina sequencing method (Beckman Coulter Genomics). Transpositional screen was performed with himarl transposons on PYE plates as previously described in ref. 43. The exact positions of three himar1 insertion sites into the ptsP locus (Fig. 3a) have been determined by semi-arbitrary PCR. The presence of himarl transposons into the pts $P$ locus was checked by PCR with primers (926 and 927) hybridizing upstream and downstream of ptsP. For E. coli, antibiotics were used at the following concentrations ( $\mu \mathrm{g} \mathrm{ml}^{-1}$; in liquid/solid medium): ampicillin (50/100), kanamycin (30/50), oxytetracycline (12.5/12.5). For C. crescentus, media were supplemented with kanamycin $(5 / 20)$, oxytetracycline $(1 / 2.5)$ where appropriate. The doubling time of Caulobacter strains was calculated in exponential phase $\left(\mathrm{OD}_{660}: 0.2-0.5\right)$ using $\mathrm{D}=\left(\ln (2) \cdot\left(\mathrm{T}_{(\mathrm{B})}-\mathrm{T}_{(\mathrm{A})}\right)\right) /\left(\ln \left(\mathrm{OD}_{660(\mathrm{~B})}\right)-\ln \left(\mathrm{OD}_{660(\mathrm{~A})}\right)\right)$ and normalized according to the wild-type strain. E. coli S17-1 and E. coli MT607 helper strains were used for transferring plasmids to C. crescentus by bi- and tri-parental mating, respectively. In-frame deletions were created by using pNPTS138-derivative plasmids and by following the procedure described previously in ref. 44 .

Flow cytometry analysis. DNA content was measured using fluorescenceactivated cell sorting (FACS). Cells were fixed in ice-cold $70 \%$ ethanol. Fixed samples were then washed twice in FACS staining buffer $(10 \mathrm{mM}$ Tris $\mathrm{pH} 7.2$, $1 \mathrm{mM}$ EDTA, $50 \mathrm{mM}$ NaCitrate, $0.01 \%$ Triton X-100) containing $0.1 \mathrm{mg} \mathrm{ml}^{-1}$ RNaseA and incubated at room temperature (RT) for $30 \mathrm{~min}$. Cells were then collected by centrifugation for $2 \mathrm{~min}$ at $8,000 \mathrm{~g}$, resuspended in $1 \mathrm{ml}$ FACS staining buffer containing $0.5 \mu \mathrm{M}$ Sytox Green Nucleic acid stain (Life Technologies), and incubated at RT in the dark for $5 \mathrm{~min}$. Samples were analysed in flow cytometer (FACS Calibur, BD Biosciences) at laser excitation of $488 \mathrm{~nm}$. At least $1 \times 10^{4}$ cells were recorded in triplicate for each experiment. Gate for cells in G1 phase was determined with a sample of wild-type cells treated with Rifampicin $\left(2.5 \mu \mathrm{g} \mathrm{ml}^{-1}\right)$ for $3 \mathrm{~h}$. Percentage of gated G1 cells of each strain was then normalized using gated G1 cells of the wild-type strain as reference.

Synchronization of cells. For synchrony, cells were grown in $200 \mathrm{ml}$ of PYE $\left(\mathrm{OD}_{660} \sim 0.8\right)$, collected by centrifugation for $15 \mathrm{~min}$ at $6,000 \mathrm{~g}, 4^{\circ} \mathrm{C}$; resuspended in $60 \mathrm{ml}$ of ice-cold $20 \mathrm{mM}$ phosphate $\left(\mathrm{PO}_{4}^{3-}\right.$ ) buffer and combined with $30 \mathrm{ml}$ of Ludox LS Colloidal Silica (30\%; Sigma-Aldrich) ${ }^{45}$. Cells resuspended in Ludox was centrifuged for $40 \mathrm{~min}$ at $9,000 \mathrm{~g}, 4^{\circ} \mathrm{C}$. Swarmer cells, corresponding to the bottom band, were isolated, washed twice in ice-cold $\mathrm{PO}_{4}^{3-}$ buffer and finally resuspended in prewarmed PYE media for growth at $30^{\circ} \mathrm{C}$. Samples were collected every $15 \mathrm{~min}$ for western blot, microscopy and FACS analyses.

Light and fluorescent microscopy. All strains were imaged during exponential growth phase after immobilization on $1 \%$ agarose pads ${ }^{41}$. Microscopy was performed using Axioskop microscope (Zeiss), Orca-Flash 4.0 camera (Hamamatsu) and Zen 2012 software (Zeiss). Images were processed with ImageJ. Supplementary Movie 1 was done with Debut Video Capture Software.

Detection of intracellular (p)ppGpp levels. (p)ppGpp levels were visualized as described previously in ref. 13. Briefly, strains were grown overnight in PYE and then diluted for a second overnight culture in M5GG (low-phosphate medium M5G supplemented with $1 \mathrm{mM}$ glutamate). Then, cells were diluted a second time in M5GG and grown for $3 \mathrm{~h}$ to reach an $\mathrm{OD}_{660}$ of 0.4. Cells were split into two parts and washed twice with P5G-labelling buffer (M5G without $\mathrm{NH}_{4}^{+}$and with $12.2 \mathrm{mM} \mathrm{NaCl}$ and $3.9 \mathrm{mM} \mathrm{KCl}$ instead of $\mathrm{Na}_{2} \mathrm{HPO}_{4}$ and $\mathrm{KH}_{2} \mathrm{PO}_{4}$ ). In all, $1 \mathrm{ml}$ of cells were then resuspended in $225 \mu \mathrm{l}$ of P5G-labelling $(-\mathrm{N})$ or M5G-labelling $(+\mathrm{N})$ supplemented with $25 \mu \mathrm{l}$ of $\mathrm{KH}_{2}^{32} \mathrm{PO}_{4}$ at $100 \mu \mathrm{Ci} \mathrm{ml}{ }^{-1}$ and incubated for $2 \mathrm{~h}$ with shaking ( 450 r.p.m.) at $30^{\circ} \mathrm{C}$. Then, samples were extracted with an equal volume of $2 \mathrm{M}$ formic acid, placed on ice for $30 \mathrm{~min}$ and then stored overnight at $-20^{\circ} \mathrm{C}$. All cell extracts were pelleted at $18,000 \mathrm{~g}$ for $3 \mathrm{~min}$ and $6 \times 2 \mu \mathrm{l}$ of supernatant was spotted onto a polyethyleneimine plate (Macherey-Nagel). Polyethyleneimine plates were then developed in $1.5 \mathrm{M} \mathrm{KH}_{2} \mathrm{PO}_{4}(\mathrm{pH} 3.4)$ at RT. Finally, TLC plates were imaged on a MS Storage Phosphor Screen (GE Healthcare) and analysed with Cyclone Phosphor Imager (PerkinElmer). For hydrolase experiments (Fig. 7d), cells were incubated $1 \mathrm{~h}$ in P5G supplemented with xylose $(0.1 \%)$. Then, cells were washed twice with P5G-labelling and 
resuspended in P5G-labelling ( $-\mathrm{N}$ ) supplemented with $\mathrm{KH}_{2}^{32} \mathrm{PO}_{4}$, xylose (0.1\%) and with $(+\mathrm{N})$ or without $(-\mathrm{N})$ glutamine $(9.3 \mathrm{mM})$.

BTH assays. BTH assays were performed as described previously in refs 23 and 42. Briefly, $2 \mu \mathrm{l}$ of MG1655 cyaA::frt (RH785), MG1655 cyaA::frt $\Delta n p r$ (RH2122), MG1655 cyaA::frt $\Delta p t s P \Delta p t s I$ (RH2124) strains expressing T18 and T25 fusions were spotted on MacConkey Agar Base plates supplemented with ampicillin, kanamycin, maltose (1\%) and IPTG (1 mM) and incubed for 3-4 days at $30^{\circ} \mathrm{C}$. All proteins were fused to T25 at their N-terminal extremity (pKT25) or to the T18 at their N- (pUT18C) or C-terminal (pUT18) extremity. BTH assays in both directions (T25-X with T18-Y or T25-Y with T18-X) gave similar results.

The $\beta$-galactosidase assays were performed as described in ref. 46 . Briefly, $50 \mu \mathrm{l}$ E. coli BTH strains cultivated overnight at $30^{\circ} \mathrm{C}$ in LB medium supplemented with kanamycin, ampicillin and IPTG $(1 \mathrm{mM})$ were resuspended in $800 \mu \mathrm{l}$ of $\mathrm{Z}$ buffer $\left(60 \mathrm{mM} \mathrm{Na}_{2} \mathrm{HPO}_{4}, 40 \mathrm{mM} \mathrm{NaH} \mathrm{PO}_{4}, 10 \mathrm{mM} \mathrm{KCl}, 1 \mathrm{mM} \mathrm{MgSO}\right)_{4}$ ) and lysed with chloroform. After the addition of $200 \mu \mathrm{l}$ ONPG $\left(4 \mathrm{mg} \mathrm{ml}^{-1}\right)$, reactions were incubated at $30^{\circ} \mathrm{C}$ until colour turned yellowish. Reactions were then stopped by the addition of $500 \mu \mathrm{l}$ of $1 \mathrm{M} \mathrm{Na}_{2} \mathrm{CO}_{3}$, and absorbance at $420 \mathrm{~nm}$ was measured. Miller units are defined as $\left(\mathrm{OD}_{420} \times 1,000\right) /\left(\mathrm{OD}_{590} \times \mathrm{t} \times \mathrm{v}\right)$, where, ' $\mathrm{OD}_{590}$ ' is the absorbance at $590 \mathrm{~nm}$ of the cultures before the $\beta$-galactosidase assays, ' $t$ ' is the time of the reaction ( $\mathrm{min}$ ) and ' $\mathrm{v}$ ' is the volume of cultures used in the assays ( $\mathrm{ml}$ ). All the experiments were performed with three biological replicates and Miller units of the T25-X T18-ZIP combination were used as a blank and substracted.

Immunoblot analysis. Immunoblot analyses were performed as described in ref. 46 , with the following primary antibodies: $\alpha$-Flagellin (1:5,000; ref. 47), $\alpha$ FLAG (1:5,000; Stratagene), $\alpha$-MreB (1:5,000; ref. 46) and secondary antibodies: $1: 10,000$ anti-mouse (for $\alpha$-FLAG) or 1:7,500 anti-rabbit (for all the others) linked to peroxidase (GE Healthcare), and visualized thanks to Western Lightning PlusECL chemiluminescence reagent (Biorad) and ImageQuant LAS400 (GE Healthcare)

Preparation of fractions containing EI ${ }^{\mathrm{Ntr}}$ or EI ${ }^{\mathrm{Ntr}}{ }_{\text {L830. }}$. Fractions containing EI ${ }^{\mathrm{Ntr}}$ or $\mathrm{EI}^{\mathrm{Ntr}}{ }_{\text {L830 }}$ proteins were purified from NA1000 and NA1000 pts $P_{L 830}$ (RH1748) strains, respectively. C. crescentus strains were grown in $150 \mathrm{ml}$ PYE liquid media $\left(\mathrm{OD}_{660} \sim 0.7\right)$, collected by centrifugation for $15 \mathrm{~min}$ at $6,000 \mathrm{~g}, 4^{\circ} \mathrm{C}$, washed by ice-cold $20 \mathrm{mM}$ phosphate buffer and then resuspended in $5 \mathrm{ml}$ ice-cold phosphate buffered-saline containing $0.05 \%$ Triton X-100, complete EDTA-free antiproteases, $20 \mathrm{mg} \mathrm{ml}^{-1}$ lysozyme, $10 \mathrm{U} \mathrm{ml}^{-1}$ DNase I. Cells were first lysed by sonication, then zirconium beads were added and cells were disrupted by Fastprep cycles $(5 \times 20 \mathrm{~s})$. Lysates were pelleted at $15000 \mathrm{~g}$ at $4{ }^{\circ} \mathrm{C}$ and then resuspended in $500 \mu \mathrm{l}$ of buffer containing $25 \mathrm{mM}$ Tris/ $\mathrm{HCl} \mathrm{pH} 7.5,10 \mathrm{mM} \mathrm{MgCl}_{2}, 1 \mathrm{mM}$ DTT.

\section{Autophosphorylation levels of El ${ }^{\mathrm{Ntr}}$ and $\mathrm{EI}^{\mathrm{Ntr}}{ }_{\text {L830. }}\left[{ }^{32} \mathrm{P}\right] \mathrm{PEP}$ was prepared} enzymatically as described previously in ref. 48 . Briefly, $50 \mu \mathrm{l}$ reaction solution containing $100 \mathrm{mM}$ triethylamine/ $\mathrm{HCl} \mathrm{pH} 7.6,15 \mathrm{mM} \mathrm{KCl}, 3 \mathrm{mM} \mathrm{MgCl}_{2}, 165 \mu \mathrm{M}$ PEP, $1 \mathrm{mM}$ pyruvate, $5 \mu \mathrm{M}$ ATP, $60 \mu \mathrm{Ci}\left[\gamma^{32} \mathrm{P}\right]$-ATP $\left(5,000 \mathrm{Ci} \mathrm{mmol}^{-1}\right)$ and 40 units of pyruvate kinase (Sigma) were incubated at $30^{\circ} \mathrm{C}$ for $2 \mathrm{~h}$. Phosphorylation assays were performed in $20 \mu \mathrm{l}$ of solution containing $10 \mu \mathrm{l}$ of proteins extract (containing $\mathrm{EI}^{\mathrm{Ntr}}$ or $\mathrm{EI}^{\mathrm{Ntr}} \mathrm{L830}$ ), $25 \mathrm{mM}$ Tris/ $\mathrm{HCl} \mathrm{pH} 7.5,10 \mathrm{mM} \mathrm{MgCl}_{2}, 1 \mathrm{mM}$ DTT, glutamine $(0,2,5$ or $10 \mathrm{mM})$ and $0.5 \mu \mathrm{l}$ of $\left[{ }^{32} \mathrm{P}\right] \mathrm{PEP}$ solution at $37^{\circ} \mathrm{C}$ for $30 \mathrm{~min}$. Then, $5 \mu \mathrm{l}$ of $5 \times$ SDS-PAGE loading buffer were added to the samples. Proteins were subjected to electrophoresis in a 10\% SDS-polyacrylamide gel. SDSpolyacrylamide gels were then dried and imaged on a MP Phosphor system (Packard) and analysed with Cyclone Phosphor Imager (PerkinElmer). Analysis of radioactive spots reveals three bands at different size $(\sim 50,80$ and $90 \mathrm{kDa})$. The band corresponding to $\sim 80 \mathrm{kDa}$, absent in protein extracts from the $\Delta p t s P$ strain, was determined as $\mathrm{EI}^{\mathrm{Ntr}}$ or $\mathrm{EI}^{\mathrm{Ntr}}{ }_{\mathrm{L} 83 \mathrm{Q}}$.

In vivo phosphorylation of EIIA ${ }^{\text {Ntr. }}$. Strains containing pXMCS2-3FLAG-ptsN were grown overnight in PYE supplemented with kanamycin and then diluted for a second overnight culture in M5GG (low-phosphate medium M5G supplemented with $1 \mathrm{mM}$ glutamate) supplemented with kanamycin. Then, cells were diluted in M5GG with or without xylose (0.1\%), and grown for $3 \mathrm{~h}$ to reach an $\mathrm{OD}_{660}$ of 0.5 . In all, $1 \mathrm{ml}$ of cells were washed twice with P5G-labelling buffer (M5G without $\mathrm{NH}_{4}^{+}$and with $12.2 \mathrm{mM} \mathrm{NaCl}$ and $3.9 \mathrm{mM} \mathrm{KCl}$ instead of $\mathrm{Na}_{2} \mathrm{HPO}_{4}$ and $\mathrm{KH}_{2} \mathrm{PO}_{4}$ ). Cells were then resuspended in $225 \mu \mathrm{l}$ of P5G-labelling, P5X-labelling (xylose $0.1 \%$ ) or P5XQ-labelling (xylose $0.1 \%$, glutamine $9.3 \mathrm{mM}$ ) supplemented with $25 \mu \mathrm{l}$ of $\mathrm{KH}_{2}^{32} \mathrm{PO}_{4}$ at $100 \mu \mathrm{Ci} \mathrm{ml}{ }^{-1}$ and incubated for $2 \mathrm{~h}$ with shaking ( 450 r.p.m.) at $30^{\circ} \mathrm{C}$. Samples were collected for $2 \mathrm{~min}$ at 12,000 r.p.m., resuspended in $50 \mu \mathrm{l}$ of lysis buffer $(50 \mathrm{mM}$ Tris pH 7.0, $80 \mathrm{mM}$ EDTA, $150 \mathrm{mM} \mathrm{NaCl}$, $4 \%$ Triton X-100) and incubated for $2 \mathrm{~min}$ at $4{ }^{\circ} \mathrm{C}$. Then, $900 \mu \mathrm{l}$ of low-salt buffer ( $50 \mathrm{mM}$ Tris pH 7.0, $100 \mathrm{mM} \mathrm{NaCl}, 50 \mathrm{mM}$ EDTA, 2\% Triton X-100) were added and samples were collected for $15 \mathrm{~min}$ at $4{ }^{\circ} \mathrm{C}$. Supernatants were mixed with antiFLAG M2 magnetic beads (Sigma) previously washed three times with TBS buffer and twice with low-salt buffer. Samples were incubated on a rotating shaker for $90 \mathrm{~min}$ at $4{ }^{\circ} \mathrm{C}$, and beads were washed once with cold low-salt buffer and twice with cold high-salt buffer (50 mM Tris pH 7.0, $500 \mathrm{mM} \mathrm{NaCl}, 50 \mathrm{mM}$ EDTA, $0.1 \%$
Triton X-100). Magnetic beads were then resuspended in $20 \mu$ of $3 \times$ SDS loading buffer and $5 \mu \mathrm{l}$ of $0.5 \mathrm{mg} \mathrm{ml}^{-1}$ of 3FLAG peptide (Sigma) were added to each sample. After $10 \mathrm{~min}$ incubation with shaking (1,300 r.p.m.), proteins were subjected to electrophoresis in a $12 \%$ SDS-polyacrylamide gel. SDS-polyacrylamide gels were then dried and imaged on a MP Phosphor system (Packard) and analysed with Cyclone Phosphor Imager (PerkinElmer). Band intensities were quantified with ImageJ software by using the WT $(-\mathrm{Xyl},-\mathrm{N})$ as the background.

\section{References}

1. Klosinska, M. M., Crutchfield, C. A., Bradley, P. H., Rabinowitz, J. D. \& Broach, J. R. Yeast cells can access distinct quiescent states. Genes Dev. 25, 336-349 (2011).

2. Errington, J. Regulation of endospore formation in Bacillus subtilis. Nat. Rev. Microbiol. 1, 117-126 (2003).

3. Poindexter, J. S. Biological properties and classification of the Caulobacter group. Bacteriol. Rev. 28, 231-295 (1964).

4. Chiaverotti, T. A., Parker, G., Gallant, J. \& Agabian, N. Conditions that trigger guanosine tetraphosphate accumulation in Caulobacter crescentus. J. Bacteriol. 145, 1463-1465 (1981)

5. Gorbatyuk, B. \& Marczynski, G. T. Regulated degradation of chromosome replication proteins DnaA and CtrA in Caulobacter crescentus. Mol. Microbiol. 55, 1233-1245 (2004).

6. England, J. C., Perchuk, B. S., Laub, M. T. \& Gober, J. W. Global regulation of gene expression and cell differentiation in Caulobacter crescentus in response to nutrient availability. J. Bacteriol. 192, 819-833 (2010).

7. Hallez, R., Bellefontaine, A.-F., Letesson, J.-J. \& De Bolle, X. Morphological and functional asymmetry in $\alpha$-proteobacteria. Trends. Microbiol. 12, 361-365 (2004).

8. Potrykus, K. \& Cashel, M. (p)ppGpp: Still Magical? Annu. Rev. Microbiol. 62, 35-51 (2008).

9. Dalebroux, Z. D. \& Swanson, M. S. ppGpp: magic beyond RNA polymerase. Nat. Rev. Microbiol. 10, 203-212 (2012).

10. Wang, J. D., Sanders, G. M. \& Grossman, A. D. Nutritional control of elongation of DNA replication by (p)ppGpp. Cell 128, 865-875 (2007).

11. Maisonneuve, E., Castro-Camargo, M. \& Gerdes, K. (p)ppGpp controls bacterial persistence by stochastic induction of toxin-antitoxin activity. Cell 154, 1140-1150 (2013)

12. Atkinson, G. C., Tenson, T. \& Hauryliuk, V. The RelA/SpoT homolog (RSH) superfamily: distribution and functional evolution of ppGpp synthetases and hydrolases across the tree of life. PLoS ONE 6, e23479 (2011).

13. Lesley, J. A. \& Shapiro, L. SpoT regulates DnaA stability and initiation of DNA replication in carbon-starved Caulobacter crescentus. J. Bacteriol. 190 , 6867-6880 (2008).

14. Boutte, C. C. \& Crosson, S. The complex logic of stringent response regulation in Caulobacter crescentus: starvation signalling in an oligotrophic environment. Mol. Microbiol. 80, 695-714 (2011).

15. Boutte, C. C., Henry, J. T. \& Crosson, S. ppGpp and polyphosphate modulate cell cycle progression in Caulobacter crescentus. J. Bacteriol. 194, 28-35 (2011).

16. Gonzalez, D. \& Collier, J. Effects of (p)ppGpp on the progression of the cell cycle of Caulobacter crescentus. J. Bacteriol. 196, 2514-2525 (2014).

17. Reitzer, L. Nitrogen assimilation and global regulation in Escherichia coli. Annu. Rev. Microbiol. 57, 155-176 (2003).

18. Leigh, J. A. \& Dodsworth, J. A. Nitrogen regulation in bacteria and archaea. Annu. Rev. Microbiol. 61, 349-377 (2007).

19. Bloom, F. R., Levin, M. S., Foor, F. \& Tyler, B. Regulation of glutamine synthetase formation in Escherichia coli: characterization of mutants lacking the uridylyltransferase. J. Bacteriol. 134, 569-577 (1978).

20. Hogg, T., Mechold, U., Malke, H., Cashel, M. \& Hilgenfeld, R. Conformational antagonism between opposing active sites in a bifunctional RelA/SpoT homolog modulates (p)ppGpp metabolism during the stringent response [corrected]. Cell 117, 57-68 (2004).

21. Deutscher, J. et al. The bacterial phosphoenolpyruvate:carbohydrate phosphotransferase system: regulation by protein phosphorylation and phosphorylation-dependent protein-protein interactions. Microbiol. Mol. Biol. Rev. 78, 231-256 (2014).

22. Goodwin, R. A. \& Gage, D. J. Biochemical characterization of a nitrogen-type phosphotransferase system reveals that enzyme EINtr integrates carbon and nitrogen signaling in Sinorhizobium meliloti. J. Bacteriol. 196, 1901-1907 (2014).

23. Karimova, G., Pidoux, J., Ullmann, A. \& Ladant, D. A bacterial two-hybrid system based on a reconstituted signal transduction pathway. Proc. Natl Acad. Sci. USA 95, 5752-5756 (1998).

24. Pflüger-Grau, K. \& Görke, B. Regulatory roles of the bacterial nitrogen-related phosphotransferase system. Trends. Microbiol. 18, 205-214 (2010).

25. Deghelt, M. et al. G1-arrested newborn cells are the predominant infectious form of the pathogen Brucella abortus. Nat. Commun. 5, 4366 (2014). 
26. De Nisco, N. J., Abo, R. P., Wu, C. M., Penterman, J. \& Walker, G. C. Global analysis of cell cycle gene expression of the legume symbiont Sinorhizobium meliloti. Proc. Natl. Acad. Sci. 111, 3217-3224 (2014).

27. Krol, E. \& Becker, A. ppGpp in Sinorhizobium meliloti: biosynthesis in response to sudden nutritional downshifts and modulation of the transcriptome. Mol. Microbiol. 81, 1233-1254 (2011).

28. Ikeda, T. P., Shauger, A. E. \& Kustu, S. Salmonella typhimurium apparently perceives external nitrogen limitation as internal glutamine limitation. J. Mol. Biol. 259, 589-607 (1996).

29. Ronneau, S. et al. Brucella, nitrogen and virulence. Crit. Rev. Microbiol. doi:10.3109/1040841X.2014.962480 1-19 (2015).

30. Cheng, Z., Lin, M. \& Rikihisa, Y. Ehrlichia chaffeensis proliferation begins with NtrY/NtrX and PutA/GlnA upregulation and CtrA degradation induced by proline and glutamine uptake. mBio 5, e02141 (2014).

31. Brilli, M. et al. The diversity and evolution of cell cycle regulation in alpha-proteobacteria: a comparative genomic analysis. BMC. Syst. Biol. 4, 52 (2010).

32. Haseltine, W. A. \& Block, R. Synthesis of guanosine tetra- and pentaphosphate requires the presence of a codon-specific, uncharged transfer ribonucleic acid in the acceptor site of ribosomes. Proc. Natl Acad. Sci. USA 70, 1564-1568 (1973).

33. Seyfzadeh, M., Keener, J. \& Nomura, M. spoT-dependent accumulation of guanosine tetraphosphate in response to fatty acid starvation in Escherichia coli. Proc. Natl Acad. Sci. USA 90, 11004-11008 (1993).

34. Battesti, A. \& Bouveret, E. Acyl carrier protein/SpoT interaction, the switch linking SpoT-dependent stress response to fatty acid metabolism. Mol. Microbiol. 62, 1048-1063 (2006).

35. Kundig, W., Ghosh, S. \& Roseman, S. Phosphate bound to histidine in a protein as an intermediate in a novel phosphotransferase system. Proc. Natl Acad. Sci. USA 52, 1067-1074 (1964).

36. Lee, C.-R. et al. Reciprocal regulation of the autophosphorylation of enzyme INtr by glutamine and $\alpha$-ketoglutarate in Escherichia coli. Mol. Microbiol. 88, 473-485 (2013).

37. Pflüger-Grau, K., Chavarría, M. \& de Lorenzo, V. The interplay of the EIIANtr component of the nitrogen-related phosphotransferase system (PTSNtr) of Pseudomonas putida with pyruvate dehydrogenase. Biochim Biophys Acta 1810, 995-1005 (2011).

38. Sanselicio, S. \& Viollier, P. H. Convergence of alarmone and cell cycle signaling from trans-encoded sensory domains. mBio 6, e01415-e01415 (2015).

39. Karstens, K., Zschiedrich, C. P., Bowien, B., Stulke, J. \& Gorke, B. Phosphotransferase protein EIIANtr interacts with SpoT, a key enzyme of the stringent response, in Ralstonia eutropha H16. Microbiology. 160, 711-722 (2014).

40. Casadaban, M. J. \& Cohen, S. N. Analysis of gene control signals by DNA fusion and cloning in Escherichia coli. J. Mol. Biol. 138, 179-207 (1980).

41. Ely, B. Genetics of Caulobacter crescentus. Meth. Enzymol. 204, 372-384 (1991).

42. Abel, S. et al. Regulatory cohesion of cell cycle and cell differentiation through interlinked phosphorylation and second messenger networks. Mol. Cell. 43, 550-560 (2011).

43. Huitema, E., Pritchard, S., Matteson, D., Radhakrishnan, S. K. \& Viollier, P. H. Bacterial birth scar proteins mark future flagellum assembly site. Cell 124, 1025-1037 (2006)
44. Thanbichler, M. \& Shapiro, L. MipZ, a Spatial regulator coordinating chromosome segregation with cell division in Caulobacter. Cell 126, 147-162 (2006).

45. Jenal, U. \& Shapiro, L. Cell cycle-controlled proteolysis of a flagellar motor protein that is asymmetrically distributed in the Caulobacter predivisional cell. EMBO. J. 15, 2393-2406 (1996).

46. Beaufay, F. et al. A NAD-dependent glutamate dehydrogenase coordinates metabolism with cell division in Caulobacter crescentus. EMBO. J. 34, 1786-1800 (2015).

47. Mangan, E. K. et al. FlbT couples flagellum assembly to gene expression in Caulobacter crescentus. J. Bacteriol. 181, 6160-6170 (1999).

48. Rothe, F. M., Bahr, T., Stülke, J., Rak, B. \& Görke, B. Activation of Escherichia coli antiterminator BglG requires its phosphorylation. Proc. Natl. Acad Sci. USA 109, 15906-15911 (2012).

\section{Acknowledgements}

We are grateful to Patrick Viollier, Justine Collier, Christine Jacobs-Wagner, Martin Thanbichler, Urs Jenal, James Gober and Sean Crosson for providing antibodies, strains and plasmids. We thank Urs Jenal and the members of the $\mathrm{BCcD}$ team for critical reading of the manuscript and helpful discussions. S.R. and K.P. hold a FRIA (Fund for Research Training in Industry and Agriculture) fellowship from the Fonds de la Recherche Scientifique - FNRS (F.R.S.-FNRS). R.H. is a Research Associate of the F.R.S-FNRS. This work was supported by a Research Project from the F.R.S.-FNRS (PDR T.0053.13) to X.D.B., and a Research Credit from the F.R.S.-FNRS (CDR 1.5067.12) to R.H.

\section{Author contributions}

S.R. and R.H. conceived and designed the experiments. S.R. performed all the experiments except otherwise stated. K.P. constructed knock-out mutants of the PTS ${ }^{\mathrm{Ntr}}$ components. S.R. and R.H. analysed the data. X.D.B. and R.H. contributed to the reagents/materials/analysis tools. S.R. and R.H. wrote the paper.

\section{Additional information}

Supplementary Information accompanies this paper at http://www.nature.com/ naturecommunications

Competing financial interests: The authors declare no competing financial interests.

Reprints and permission information is available online at http://npg.nature.com/ reprintsandpermissions/

How to cite this article: Ronneau, S. et al. Phosphotransferase-dependent accumulation of (p)ppGpp in response to glutamine deprivation in Caulobacter crescentus. Nat. Commun. 7:11423 doi: 10.1038/ncomms11423 (2016).

This work is licensed under a Creative Commons Attribution 4.0 International License. The images or other third party material in this article are included in the article's Creative Commons license, unless indicated otherwise in the credit line; if the material is not included under the Creative Commons license, users will need to obtain permission from the license holder to reproduce the material. To view a copy of this license, visit http://creativecommons.org/licenses/by/4.0/ 